\title{
ISOLAMENTO E BIOLOGIA DE NOVOS FUNGOS CELULOLÍTICOS
}

APARECIDO OSDIMIR BERTOLIN

Orientador: Prof. Dr. JOĀO LÚCIO DE AZEVEDO

Dissertação apresentada à Escola

Superior de Agricultura "Luiz de Queiroz", da Universidade de São Paulo, para obtenção do título de Mestre em Agronomia. Área de Concentração: Microbiologia Agrícola.

PIRACICABA

Estado de São Paulo - Brasil

Setembro - 1987 
ii.

A Maria Carolína,

ao Pedro Augusto, aos meus pais e amigos DEDICO 


\section{AGRADECIUIENTOS}

Manifestamos sinceros agradecimentos a todos aqueles que contribuiram para a realização deste trabalho, especialmente:

- Prof. Dr. João Lúcio de Azevedo;

- Profa Drạ Aline Pizzirani Kleiner;

- Prof. Dr。 Flávio C.Almeida Tavares;

- Prof. Dr. Sérgio Echeverrigaray Laguna:

- MS. Maria José Vallerini;

- Coordenadores do Curso de Pós-Graduação em Microbiologia Agrícola;

- Funcionários do Laboratório: Antonio Rocha Campos, Luiz Prospero, Sandra Elisabete Rocha Campos e Carlos Alberto Nolasco;

- Funcionários do Departamento de Genética;

- Colegas do Curso de Pós-Graduação.

A todos que direta ou indiretamente contribui ram para a realização do presente trabalho. 


\section{INDICE}

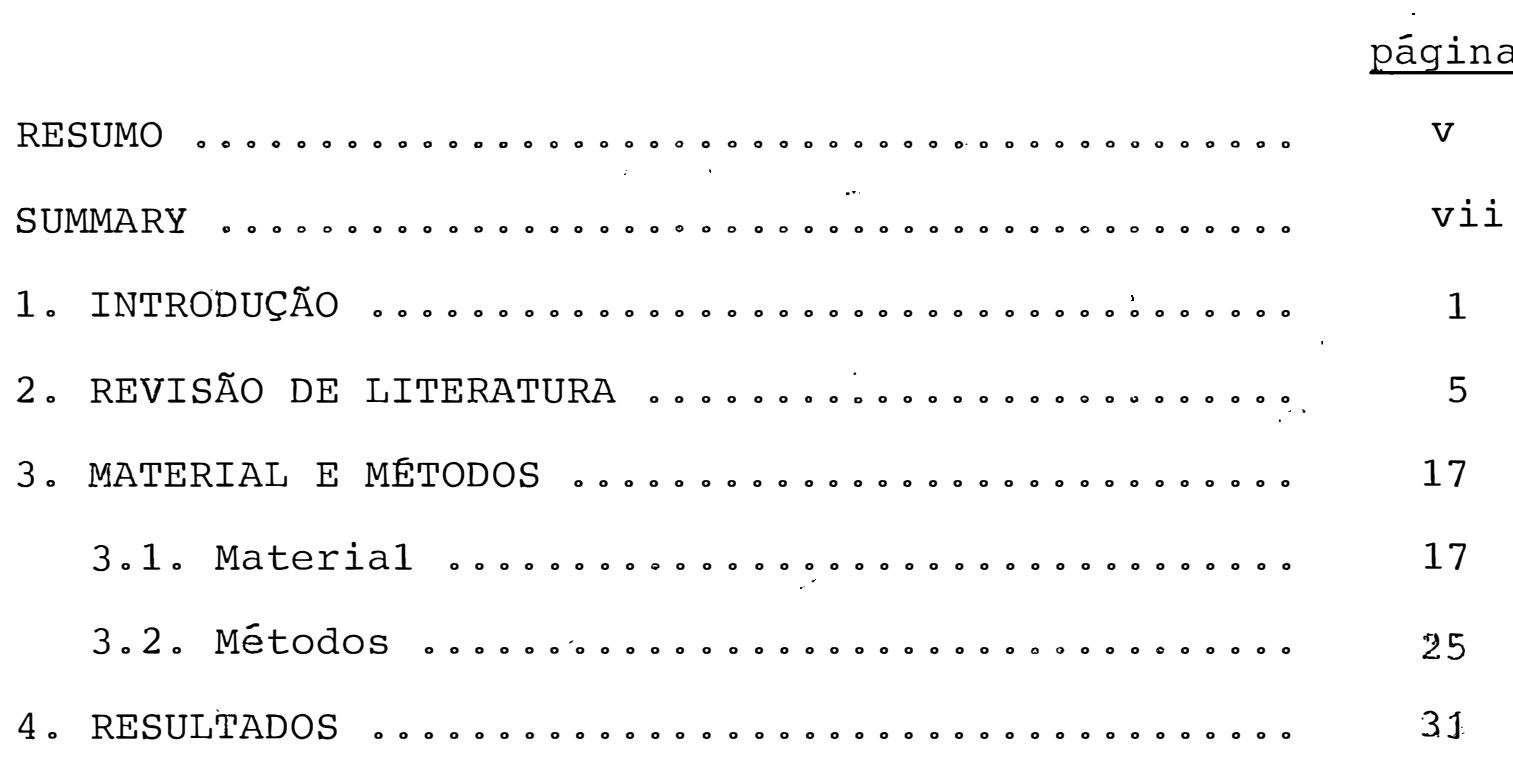

4.1. Origem do material e caracterização morfoló

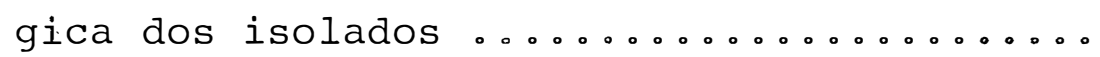

4.2. Dosągem comparativa da produção de celulo-

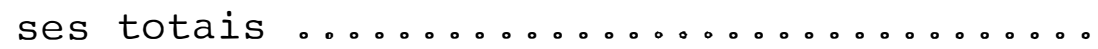

4.3. Ensaio do crescimento dos fungos em diferen tes meios e diferentes temperaturas .... 34

4.4. Produção de esporos .................. 34

4.5. Estudos citológicos ................ 34

4.6 . Dosagem da atividade enzimática ........ $4: 2$

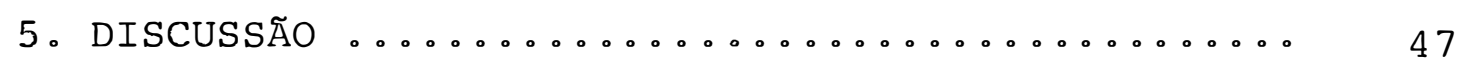

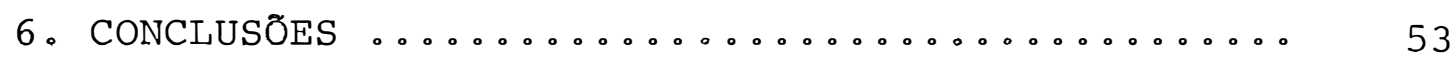

7. REFERÊNCIAS BIBLIOGRĀFICAS ........... 54 


\title{
ISOLAMENTO E BIOLOGIA DE NOVOS FUNGOS CELULOLITICOS
}

\author{
Autor: APARECIDO OSDIMIR BERTOLIN \\ Orientador: Prof。Dr。 JOÃO LÛCIO DE AZEVEDO
}

RESUMIO

Para viabilizar o aproveitamento da celulose, é necessário sua hidrólise obtendo-se resíduos de glicose; esta hidrólịse pode ser ácida ou enzimática. A hidrólise en zimática apresenta algumas vantagens sobre a ácida, embora microrganismos utilizados até agora não sejam extremamente eficientes na produção de celulases. Com o interesse ' de explorar melhor a nossa microbiota, o presente trabalho se propos à busca de fungos com alta capacidade de hidrolisar celulose, isolados a partir de duas regiões geográficas dife rentes. Foram assim obtidos 20 isolados que foram analisados e comparados com um padrão o Trichoderma reeseî QM 9414 considerado como alto produtor de celulases. Foi feito um estudo de aspectos biológicos dos 20 isolados, fixando assim bons parâmetros para estudos posteriores no tocante a classi ficação e melhoramento genético destes isolados. Especial- 
mente um dos isolados classificado como Trichoderma pseudo coningii foi considerado promissor por apresentar uma alta taxà de produção de celulases além de apresentar outras caracteristicas favoráveis para füuros estudos de genética e melhorainiento. 


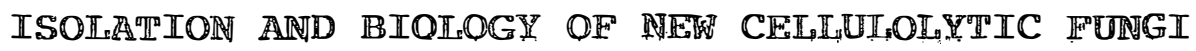

Author: APARECIDO "OSDIMIR BERTOLINT

Adviser: Prof.Dr. JO§̃O LÚCIO DE AZEVEDO

\section{SUPAPFARY}

For better uses for cellulose it must be partetioned into glucose residues and this can be done by the acid or by enzymatic hydrolisis. Some advantages can be pointed out in using the enzymatic process although strains of microorganisms used until now can still be improved to produce higher amounts of cellulases. The main goal of this work was to explore our microbiota aiming to find out new f̈ungi with high ability in breaking down cellulose. Tow different geographic regions were select and from them 20 isolateds were obtained and tested. Trichoderma reesei QM 9414 was used a standard for comparing the performance of the isolated fungi strains. Morphological and biological parameters were stablished for the 20 strains providing informations for future classification and genetic improvement programs. One of the isolates classified as - 
Trichoderma pseudo coningii, was shown to be the most promessing one giving high rates of cellulases production: it aiso presented favorable characteristics for genetic and breeding studies. 


\section{INTRODUCÃO}

Nos últimos dez anos, a preocupação dos pesquisadores e líderes do governo, na utilização de compostos orgânicos como matéria prima para a produção de álimentos, energia e produtos químicos, que possam substituir total ou parcialmente as fontes fósseis, tem sido cuidadosamente observada (GHOSE et alii, 1979)。

A constatação de que a energia fotossintética, que é renovável, rende anualmente uma produção de biomas sa em torno de $1,46 \times 10^{9}$ toneladas (NYSTRON et alliii, 1975)。 fez com que a sua utilização fosse melhor explorada. os com postos orgānicos obtidos pela fotossintese são decompostos pela natureza lentamente, e ressintetizados num ciclo periódico; ao contrário, os compostos de origens fósseis são esgo táveis, não se renovam facilmente na natureza, e os perỉodos 
para sua nova formação não podem ser estimados em anos,

e sim em Eras。

A celulose compreende cerca de $2 / 3$ de toda a matéria orgânica existente sobre a terra, e acredita-se que a produção anual de celulose atinja a casa de 100 bilhões de toneladas, o que corresponderia a $70 \mathrm{~kg}$ de celulose/dia/habi tante do Planeta (SPANO et aliiil, 1975; RYU, 1980). A produção de biomassa. é provavelmente um dosmais eficientes métodos para se aprisionar a energia solar (RYU, 1980 e GHOSE et alii, 1979)。

Considerando que a composição do resíduo celu Iósico seja: 40 - 45\% de celulose, 20 - 30\% de hemicelulose, e 40 - 25\% de lignina, acredita-se que a perda anual destes residuos sejam aproximadamente $4,4 \times 10^{8}$ toneladas de celulo으 se, 3,0 × $10^{8}$ toneladas de hemicelulose e $2,5 \times 10^{8}$ toneladas de Iignina (STUPIELO, 1980).

Tanto a celulose como a hemicelulose podem ser convertidas por hidrólise em produtos solüveis (glicose, glicose, manose e xilose, respectivamente); esta hidrólise po de ser ácida ou enzimática (CARVALHO, 1983).

Nos processos de hidrólise ácida, a técnica de utilização do ācido sulfúrico já está superada e novas técnicas estão sendo exploradas, evitando-se a degradação do produto final (glicose). Alēm disso, estes äcidos interagem 
com materiais não celulósicos, celuloses imperfeitas (cruas) e cprroem os equipamentos, resultando assim em baixo renimento, impureza no xarope, alto custo na implantação de uma usina e riscos de acidentes para os trabalhadores.

Para superar esses problemas busca-se, atualmente, a valorização da hidrólise microbiológica ou enzimāti ca. Para tanto, existe a necessidade de se explorar a nossa microbiota, para se obter microrganismos capazes de degra dação destes materiais, ou de alta produção das enzimas do complexo celulósico capaz de fazê-lo, e isto depende do desenvolvimento de processos tecnológicos e econômicos. A hidrólise ènzimática ou microbiológica se sobrepõe a " a áciá, pois, os produtos finais são de baixo peso molecular semelhantes a hexoses ou pentoses. Portanto, a bioconversão ou a conversão química destes produtos pode ser feita . e seus produtos usados como combustiveis, alimentos quimicos e alimentos propriamente ditos.

os estudos da conversão microbiológica ou enzimática são recentes e, pode-se dizer que se iniciaram a partir da mudança dos enfoques das pesquisas do U.S. Army Na tick Development Center, que deixou de combater os microrga-nismos decompositores de materiais celulósicos, passando a utilizar o seu potencial para a producão de glicose a partir desses residuos. Este enfoque foi prontamente percebido pelos Iíderes de governo e administradores de Einanciadoras de 
pesquisas acadêmicas e industriais: hoje o mundo inteiro ten ta"utilizar esta técnica e tirar proveito dela.

o presente trabalho objetivou isolamento, seleção, estudos biológicos e fisiológicos de fungos celulolíticos de ocorrência em "habitats" diversos com vistas ao meIhoramento para produção de celulases. 


\section{REVISÃO DE LITERATURA}

Para uma possivel solução dos nossos problemas de recưrsos energéticos, químicos e alimentos, a celulose surge como uma das únicas fontes renováveis de carbono e é disponivel em grande quantidade. o total de carbono fixado pela fotossintese usando energia solax é enorme, podendo- se dizer que, quase metade disto está na forma de celulose. o mais eficiente método de se aprisionar energia solar (GHOSE et aliiit, 1979).

Por se tratar de um polimero linear de glicose, composto por unidades anidroglicosídicas, unidas por 1igacões do tipo $\beta$ 1-4 a celulose pode ser utilizada na pro dução de alimentos, produtos químicos ou fermentação alcoóli ca, mas para isso ela precisa ser hidrolisada. 
As formas de hidrölise mais comumente utiliza. das 'são: o processo ácido e o enzimático. o processo ácido possui a vantagem de ser mais rápido, isto quando se usam ácidos diluidos a altas temperaturas. Este processo, porēm, è muito oneroso, pois os equipamentos são caros, gasta-se muita energia e o rendimento é baixo (cerca de 50 - 70\% do valor teórico), além do que, durante a hidrólise são formados produtos com menos de seis carbonos, que inibem o processo, in-terações do ácido com material não celulósico, corrosão do equipamento e impurezas no xarope (RYU, 1980 e GHOSE et allin, 1979).

Por sua vez, a hiarólise microbiológica ou enzimática é um processo mais demorado (24-48 horas), embora seu rendimento seja mais alto, cerca de 85-90\% do valor teórico. Este processo é conduzido a baixa temperatura e pressão, e a especificidade das enzimas para com a molécula de celulose pró duz apenas glicose como produto final (VRIGHT, 1983 e CARVALHO, 1983)。

Após publicações dos trabalhos do Dr. Ëliwyn Reese e colaboradores em 1950, os pesquisadores tem dado gran de impulso na criação de uma indústria utilizando hidrólise mi-. crobiológica ou enzimática. Muitos processos têm sido desen volvidos no sentido: de um melhor aproveitamento dos resíduos celulósicos, onde se procura avaliar os recursos florestais, que até então não eram utilizados, tais como: as sobras das madeiras de grandes florestas, residuos de indūstrias flo 
restais, restos de papéis, lixos urbanos, etc。

Todos estes residuos contêm elevadas taxas

de celulose, hemicelulose, lignina e compostos orgânicos,que também podem ser aproveitados. Infelizmente, o alto custo de uma produção enzimática em alta escala, de uma tecnologia desenvolvida para selecionar resíduos, e o próprio interesse da indústria nesta produção fazem com que o processo, no momento, seja economicamente desvantajoso na maioria dos casos.

Resse e colaboradores após muitos anos de pes quisa concluíram que a celulase não é uma enzima única, mas sim um complexo enzimático que atua sinergisticamente, e que alguns microrganismos eram capazes de degradar vários tipos de celulose, enquanto outros não possuiam esta capácidade. Foi também verificado por este grupo de pesquisadores que as enzimas eram secretadas por alguns microrganismos de forma intracelular e por outros de modo extracelular; também foi observado que a celulose pode existir em duas forma básicas: cristalina (altamente organizada e protegida por lignina) e na forma amorfa (menos organizada).

As enzimas do complexo celulolitico são sinte tizadas por fungos, actinomicetos e bactérias. De uma grande seleção de microrganismos, feita no Natick Laboratórios (REESE, 1976) O Trichoderma foi apontado como um fungo capaz 
de produzir um complexo celulolitico balanceado e ativo, e que, se caracterizava pela produção de enzimas extracelulares. Muitas outras espécies têm a atividade celulásica, mas não produzem níveis adequados de enzimas extracelulares para o uso prätico, nem para hidrólise extensiva de altas concentra ções de celulose. Värios trabalhos têm sido publicados rela cionando a prática da sacarificação utilizando Penicilliinu, Sclerotium rolfssi (SCHEWALE et alii, 1979) e Thermonospora (Ferchak et alii citados por RYU, 1980.), mas a maior parte dos trabalhos envolve celulases do $\mathfrak{H}_{\text {o }}$ viride (TOYAMA et alli. 1976 e 1977) ou T. reesei (ANDREN et alii, 1976; BRANDT et alii, 1973; GHOSE et alii, 1969; GHOSE et alii, 1972 e HOWEELI et alii, 1975). Outras espécies de minchoderma, tais como $\mathbb{P}$. Iignorum e $\mathrm{T}$. komingi i são produtores de celulases

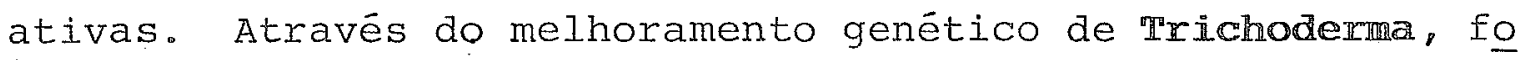
ram obtidos os mutantes QM 9123, SM 9414 (MANDELS, 1975) ,MCG 77 (GALLO et alii, 1979) e Rutgers C30 e-NTG 14 (MONTENECOURT et aliii," 1977); eles são todos derivados da linhagem QRI, que originalmente caracterizava-se ser Tr. viride e,hoje, esta espécie é reconhecida como uma nova espécie, o $\mathbb{P}$. Ireesei.

Muitos processos, para uma melhor utilização das enzimas celulolíticas, têm sido estudaảos, com atenção voltada para a otimização nos processos fermentativos e na produção das enzimas (BROWN et aliii; 1975; ANDREOTTII et 
alii, 1977: BERNAT et aliin, 1977; MAIJDELS et alii, SATTAROVA et alii, 1972 e STERNBERG, 1979), assim como avaliação dos substrados para esta produção; estes substratos podem ser resíduos da agricultura (DEMAIN, 1972; FERRER et alli.i, 19.77 e Martinez et aliii, 1974, citado por RYU, 1980), substratos solúveis, rue possuem altos níveis de celulose (SKINNNER et aliif, 1978), hemicelulose (JANICKI, 1976)。 efeito da assimilação da amônea (STERNBERG et aliii, 1979) na produção das enzimas tambëm tem sido examinado.

Quanto a forma de cultura, tanto a cultura sọ lida quanto a semi-sōlida têm sido usadas produzindo enzimas com boas"atividades e em grande quantidade "TOYAMA et alin. 1976 e VILELLA et allin, 1977). Alguns pesquisadores têm explorado o sistema de culturà continua para efetuar estudos da fisiologia (RYU et aliî, no prelo) cinética do crescimento (BROWN et alii, 1977), reações enzimáticas (PEITERSEN, 1977), produtividade pela luz (MITRA et alli

A anālise enzimática tornou-se complicada des de que se observou uma multiplicidade das enzimas e dos subs tratos. A celobiase ( $\beta-g l$ lucosidase) é medida por hidrólise de celobiose ou aril- - -glucosideos tais como P-nitrofenil- $\beta-$ -D-glicosídeo (PNPG) ou salicina; as atividades de endo e exoglucanase são expressas de acordo com o substrato, que pode ser carboximetilcelulase (endoglucanase), avicel (exo- 
glucanase), celulose de algodão, celulose de papel de filtrob, etc.. Quando se trata de trabalho quantitativo, deve-se expressar a atividade em Unidades Internacionais (REESE, 1976).

As atividades especificas das enzimas são bai xas; pode-se dizer que para a CMCase é de cerca de 10-25 Uni dades/mg de proteína, cerca de 0,6 Unidades/mg para papel de filtro e 0,02 Unidades/mg para o algodão. Os dados acima são baseados na produção e redução de açúcares (glicose), pelo método de DNS (MANDELS et aliii, 1975).

Outro método para se dosar cMcase lendoglucanase) pode ser pela viscosidade da CMCase (WOOD et alii, 1978), este método é muito sensível, pois a quebra ao acaso de uma cadeia de celulose pode reduzir a viscosidade para cerca de 50\%, mas não proporciona um aumento nos grupos redu tores. Muitos trabalhos têm sido publicaāos onde a preocupa ção central é melhorar a sensibilidade dos métodos, para se obter um resultado mais confiāvel e menos complexo (HUANG et alii, 1975; MONTENECOURT et aliii, 1978 e LEISOLA et alii, 1978)。

Concomitantemente, grandes esforços têm sido feitos no sentido de se obter novos microrganismos e/ou mutantes dos já existentes que produzam altas concentracões das enzimas, ou que sejam promissores para um estudo detalhado 
de como estas ocorrem e como isto poderia ser melhorado.

Alguns mutantes do $T_{0}$ reesei para alta produção foram obtidos por GALLO et alii (1979) e MONTENECOURT et alii (1977). Também actinomicetos termofilicos foram estuda dos por ROMANELLI et alii (1975), STUTZENBERGER (1971) e WOOD et ali (1975), e tambëm leveduras com esta capacidade foram isoladas.

A cinética da hidrólise tem sido estudada usando-se parâmetros como absorção da enzima (WIJKE et aliiị, 1975; HUANG, 1975 e MANDELS et alii, 1971), mecanismo da rea ção (GHOSE, 1979), inibição do processo enzimático (HOWELL et alii, 1975), desativação do complexo enzimático (HowELL et alii, 1978), concentração do substrato e da enzima (HUANG, 1975)。

A hidrólise enzimática foi 10 estudada por REESE et allii (1950), que denominou as enzimas como $C_{1}$ e $C_{x^{\prime}}$ " onde $\mathrm{C}_{1}$ seria o componente pré-hidrolitico, que formaria as cadeias menores de carboidratos a partir da celulose nativa; estas cadeias seriam então hidrolisadas pela enzima $C_{X}{ }$ que hidrolisaria derivados solüveis de celulose. Entretanto, ERICKSON et alii (1972) isolaram uma enzima semelhante a $C_{1}$ de S. pulverulentum que hidrolisava as extremidades da cadei a de celulose onde eram liberadas moléculas de glucose e celobiose. 
Aprimoramentos de técnicas e melhor atenção por parte dos pesquisadores, fizeram com que eles demonstras sem que existem três tipos de enzimas relacionadas com a hidrólise da celulose (WOOD et aliï, 1980) e estas são: Endo-

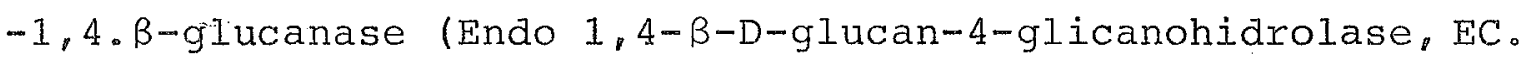
3.2.14): Celobiohidrolase (1,4-B-D-glucan celobiohidrolase , EC.3.2.1.91.) e B-glicosidae (EC.3.2.121)。

Endo-1,4-glucanase é uma enzima que hidrolisa as cadeias ao acaso, resultando numa redução rápida do comprimento da cadeia ou no grau de polimerização junto com um lento aumento nos grupos de redução. A configuração $\beta$-glico se é conservada e o produto final é uma mistura de glicose e celobiose. "Exo-1,4.ß-glucanase é uma enzima que remove unidades de glucose ou celobiose das extremidades não redutoras das cadeias, o que resulta num aumento nos grupos redutores, acompanhado de pouca mudança na fluidez.

As endoglucanases atacam derivados de celulose tais como CMC, mas não atacam a forma cristalina; celobiohidro lase age tanto nas formas cristalina quanto na amorfa. Estas enzimas são incapazes de atacarem derivados de celulose.

Por sua vez, celobiose ou $\beta$-glicosidases agem sobre celodextrina e o produto final pode ser determinado pe los métodos de D.Nitro-salicilico (DNS) ou Somogyi e Nelson (WOOD et alii, 1972)。 
Estudos mais detalhados sobre os componentes enzimāticos do sistema celulolitico mostram multiplicidade nos componentes do sistema enzimático. A natureza e origem. destas diferentes formas com atividades semelhantes se encon tram muito bem estudada. NAKAYAMA et alinil (1976) e GONG en alii (1977), propõem explicações para esta multiplicidade e afirmam que pode ser um pröcesso genético transducional, por ação de protease ou pelo processo de glicosilações da cadeia polipeptidica, que servem para proteção das proteínas na sua atividade extracelular (GUM et alini, 1977; WILLICK et allin, 1985 e SPREY et alliii, 1984)。

BERGHEN et ali $i$ i (1976) purificaram duas das quatro exoglúcanases encontradas $\in m$ T. Ieesei e verificaram que elas apresentavam uma baixa atividade em celulose nativa, embora fossem capazes de formar fibras livres em substratos como pa pel de filtro.

Outros estudos sobre heterogeneidade foram feitos e demonstraram ser muito úteis para se elucidar os estudos, rois em $\mathbb{T}$ ir ichoderma komilingi而 foram encontrados 10 componentes do complexo celulolítico, sendo duas celobiohidrolases, duas $\beta-g l i-$ cosidases e seis endoglucanases (WOOD \& MCCRAE, 1978); também foram isolados de outros microrganismos como scresotrum pulverutentum (ERICKSSON, 1981), Penicillinum funiculosum (WOOD et allii, 1980)。 P. emersoni (MCCHALE \& COUGHIAN, 1981) e Schizophyll Ium comminume 
(WILLICK et alii, 1984).

As enzimas do complexo celulolitico atuam de 0

modo cooperativo sobre a celulose e, segundo estudos feitos por WOOD (1975), existe uma relação de estequiometria entre a quantidade de endoglucanase e exoglucanase para se ter uma maior atividade.

\section{Vários autores como JIRESOVA et alli i (1983),} FUSEE et alii (1972) e HERR (1979), estudaram o controle do sistema celulolitico e concluíram que ele sofre tanto contro le genētico quanto bioquimico. Observaram também que a sìntese das enzimas è controlada pelos mecanismos de indução e repressão çatabōlica; tais mecanismos foram discutidos em oụ. tros sistemas enzimáticos.

Inumeras fontes de carbono foram ensaiadas pa ra se obter o melhor indutor para as enzimas e, a celulose tem sido reconhecida como o melhor indutor do complexo enzimático (MANDELS, 1975 e WILLIK et alii, 1984). Outros indutores ensaiados incluem a soforose (2-0- - -D-glicopiranosil D-glicose), um dissacarídeo que ocorre como impureza na glicose comercial e a lactose (MANDELs, 1975). A celulose, celobiose e a lactose só se tornam efetivas na indução em altas concentrações, já a soforose é ativa a baixa concentração (STERNBERG et alii., 1979)。 
Ainda não se conseguiu um indutor natural que não reprima a biossintese de celulases e, a repressão ocorre por um catabólico da glicose; quando adiciona-se glicose na cultura onde ocorre a biossintese das enzimas, ela é cessada imediatamente, até que a glucose seja exaurida do meio ou que a concentração atinja um nível abaixo do crítico que è aproximadamente de 0,1 $\mathrm{mg} / \mathrm{mI}$ (GALLO et alii, 1979)。

As enzimas produzidas por $\mathbb{T}_{0}$ reesei com celulose ou lactose como fonte única de carbono, são tidas como um completo e bem balanceado complexo celulósico, visto que outras fontes não o fazem (STERNBERG et allïi, 1979)。

NIZIZAWA et alii (1971), acreditam que a repressão catabólica da biossintese de celulase inautivas ocor rem a nivel de transcrição, baseados nos seus estudos com ac tidiona D e puromicina, usando aminoácidos marcados. STERNBERG et alii (1980) estudou o papel da soforose na producão das enzimas dö complero celulolitico e afirmaram que a soforose tem dois papéis regulatórios na produção das enzimas em T. reesei, um é a repressão de $\beta$-glucosidase e o outro é a indução de endo e exoglucanase.

A estabilidade da enzima é muito grande e, testes quanto à temperatura indicaram que as enzimas do $\mathbb{P}^{\text {. }}$ reesei são estāveis a $50^{\circ} \mathrm{C}$, podendo ser guardadas refrigieradas, congeladas, liofilizadas ou precipitadas por acetona ou 


\section{1}

etanol, não alterando a sua atividade, por muitos anos.

A criação de uma indústria para produção em alta escala dos componentes celuliticos ainda apresentam gran des problemas, tais como, investimento alto na produção industrial, produção não eficiente de enzimas, falta de financiamento de pesquisas nesta área e falta de visão para o furturo dos empresários do ramo.

Para tanto, a necessidade de se buscar novos microrganismos ou explorar melhor a nossa microbiota, será uma forma de se obter os elementos básicos de perspectivas de utilização do sistema no nosso país. A partir de microrganismos potenciais na produção destas enzimas, a sequência de eventos para o seu melhor aproveitamento e o seu melhoramento genëtico se desencadearā facilmente. Alēm disso, pelo fa to de ser o Brasil un Pais tropical e possuidor de grandes reservas florestais, presume-se que haja-facilidade de, ' em ambientes apropriados para o isolamento de novas linhagens, que sejam superiores, às utilizadas normalmente. 


\title{
3. MATERIAL E METODOS
}

\author{
3.1. Material
}

3.1.1. Trichoderma reesei QM9414 (U.S. Armmy Nactick Research and Development Center Conard, Massa chusetts, USA)

3.1.2. Meio de enriquecimento e isolamento de micror ganismos celuloliticos (AARONSON, 1970) (MM)

Extrato de solo ........... 0,05 ml

$\mathrm{K}_{2} \mathrm{HPO}_{4} \ldots \ldots \ldots \ldots \ldots \ldots \ldots \ldots \ldots \ldots, 0 \ldots \ldots$

$\mathrm{MgSO}_{4} \circ 7 \mathrm{H}_{2} \mathrm{O} \ldots \ldots \ldots \ldots \ldots \ldots, 0 \ldots \ldots$ g

$\mathrm{NH}_{4} \mathrm{Cl} \ldots \ldots \ldots \ldots \ldots \ldots \ldots \ldots \ldots \ldots \ldots \ldots$ 
Āgua destilada ............ $100 \mathrm{ml}$

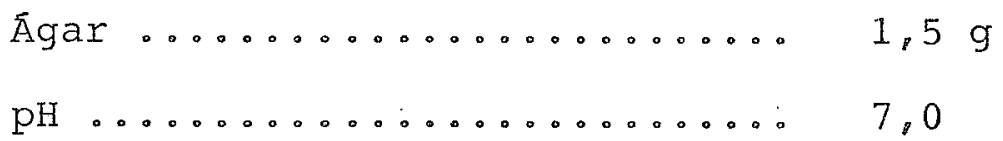

Como fonte de carbono, usou-se 0,5 g de pó de celulose, tiras de papel de filtro ou de jornal.. Autoclavonimse por 20 minutos a $120^{\circ} \mathrm{C}$.

\subsubsection{Extrato de solo}

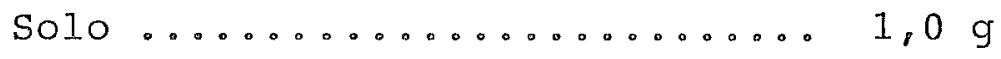

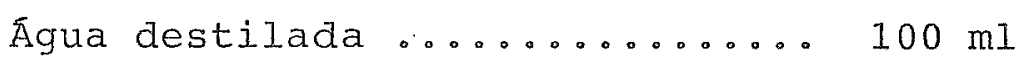

Autoclavou-se por 20 minutos a $120^{\circ} \mathrm{C}$.

3.1.4. Meio completo para fungos (MC) (PONTECORVO et alii, 1953), modificado por AREVEDO \& COS

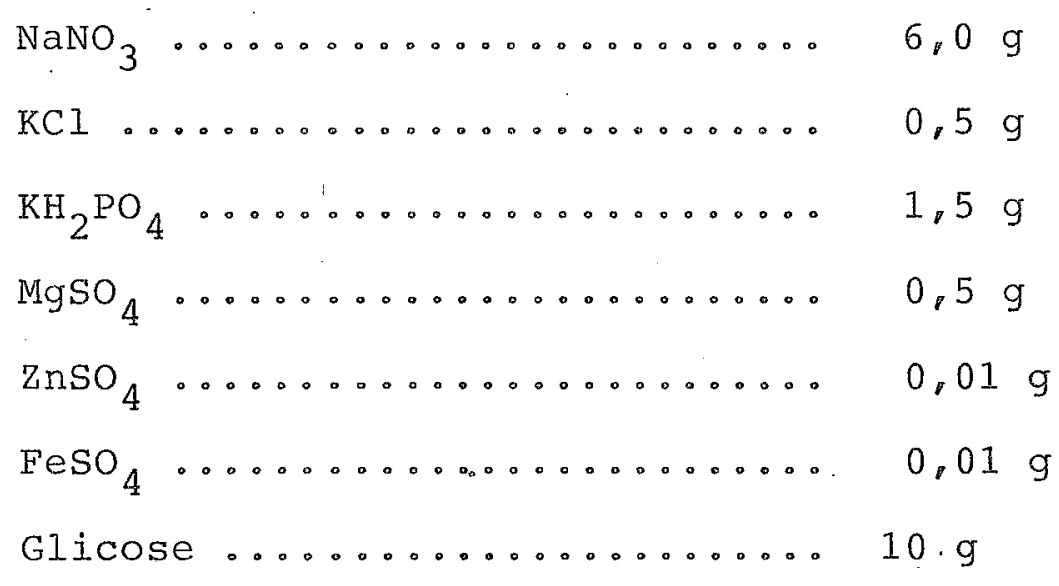


Peptona ................ 2,0 g

Extrato de levedura .......... 2,0 g

Caseina hidrolisada ......... 1,5 g

Ágar ................ $18 \mathrm{~g}$

Solução de vitaminas .......... 1,0 ml

Água destilada ............ $1000 \mathrm{ml}$

$p H \ldots \ldots \ldots \ldots \ldots \ldots \ldots \ldots \ldots \ldots \ldots \ldots \ldots \ldots$

Autoclavou-se por 20 minutos a $120^{\circ} \mathrm{C}$.

3.1.5. Meio mineral para celuloliticos (AMARAL et alii, 1967)

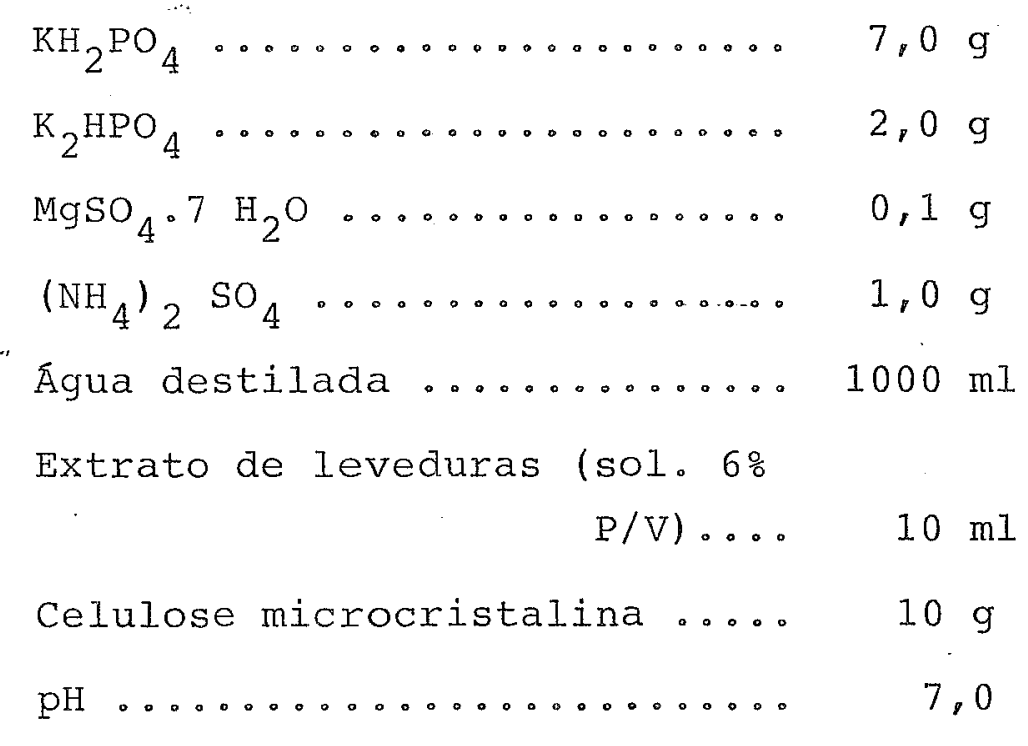

Empregou-se 18,0 g de ágar para o meio sólido; âutúclavou-se por 20 minutos a $120^{\circ} \mathrm{C}$. 


\subsubsection{Preparo da cellulose ácida}

309 de celulose (pulverizada) em beaker de

51 .

Adicionar $400 \mathrm{ml}$ de äciảo $\therefore$ orto-nosfórico

(88\%) e agitar por 2 horas a $1^{\circ} \mathrm{C}$ (na geladeira). Após, adicionar 2 litros de $\mathrm{H}_{2} \mathrm{O}_{\mathrm{d}^{\prime \prime}}$ e agitar rapidamente. Filtrar, à vācuo em gase 5 dobras e 2 camadas de papel filtro whatman nㅇ․ 1 .

Ressuspender a pasta em 2 Iitros de $\mathrm{H}_{2} \mathrm{O} \cdot \mathrm{e}$ filtrax como antes; o precipitado colocar em 1 litro : de $\mathrm{Na}_{2} \mathrm{CO}_{3}$ a. $2 \%$ Homogeneizar por 5' e estocar por $12 \mathrm{~h}$. Iuvar com 5. Iitros de $\mathrm{H}_{2} \mathrm{O}$ e filtrar. Centrifugar o precipitado a $1.0 .000 \mathrm{~g}$ por 5' e homogeneizar o "pellet" por 5'.A suspensão resultante deverá ter pH próximo de $6,5 \pm 0,1$. Secar a $80^{\circ} \mathrm{C}$, até ficar bem seco. 
3.1.7. Meio de ágar celulose ácida (TANSEY, 1971)

$\mathrm{NH}_{4} \mathrm{H}_{2} \mathrm{PO}_{4} \ldots \ldots \ldots \ldots \ldots \ldots \ldots \ldots \ldots \ldots \ldots \ldots \ldots$

$\mathrm{KH}_{2} \mathrm{PO}_{4} \ldots \ldots \ldots \ldots \ldots \ldots \ldots \ldots \ldots \ldots, 0 \ldots \ldots$

$\mathrm{K}_{2} \mathrm{HPO}_{4} \ldots \ldots \ldots \ldots \ldots \ldots \ldots \ldots \ldots \ldots \ldots, 0 \ldots \ldots$

$\mathrm{MgSO}_{4} \circ 7 \mathrm{H}_{2} \mathrm{O} \ldots \ldots \ldots \ldots \ldots, 0,8 \mathrm{~g}$

Tiamina $\ldots \ldots \ldots \ldots \ldots \ldots \ldots \ldots \ldots \ldots$

Extrato de levedura ......... $0,5 \mathrm{~g}$

Adenina $\ldots \ldots \ldots \ldots \ldots \ldots \ldots \ldots \ldots \ldots \ldots$

Adenosina ............. $8,0 \mathrm{mg}$

Celulose ácida (seca) ....... 5, $0 \mathrm{~g}$

Ágar ................... 17,0 g

Água destilada ............... $1000 \mathrm{ml}$

Autoclavou-se por 20 minutos a $120^{\circ} \mathrm{C}$.

3.1.8. Heio de ágar celulose ácida (HEDGER, 1982 modificado)

$\mathrm{KH}_{2} \mathrm{PO}_{4} \ldots \ldots \ldots \ldots \ldots \ldots \ldots \ldots \ldots \ldots \ldots \ldots \ldots \ldots \ldots \ldots, 3,8$

$\mathrm{K}_{2} \mathrm{HPO}_{4} \ldots \ldots \ldots \ldots \ldots \ldots \ldots \ldots \ldots \ldots \ldots \ldots \ldots \ldots \ldots$

$\mathrm{MgSO}_{4} \cdot 7 \mathrm{H}_{2} \mathrm{O} \ldots \ldots \ldots \ldots \ldots \ldots, 0 \ldots \ldots, 1 \mathrm{~g}$

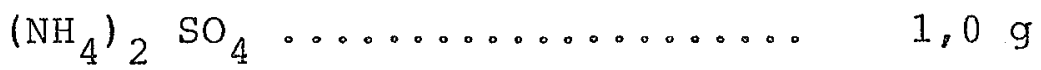

Extrato de levedura ......... $0,6 \mathrm{~g}$

Celulose ácida (sieca) ....... 5,0 g

Ágar ................ $15 \mathrm{~g}$ 
Água destilada ........... $1000 \mathrm{ml}$

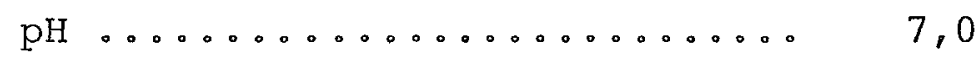

Autoclavou-se por 20 minutos a $120^{\circ} \mathrm{C}$.

3.1.9. Sollução salina

$\mathrm{NaCl} \ldots \ldots \ldots \ldots \ldots \ldots \ldots \ldots \ldots \ldots$

Agua destilada ............ $1000 \mathrm{ml}$

Autoclavou-se por 20 minutos a $120^{\circ} \mathrm{C}$.

3.1". \#0.Solução de citrato de sódio 1 R

Citrato de sódio ............ $\quad 5,9$ g

Água destilada ........... $20 \mathrm{ml}$

3.1.11.Solução pađrão de glicose

Glicose $\ldots \ldots \ldots \ldots \ldots \ldots \ldots \ldots \ldots \ldots \ldots$

Água destilada $\ldots \ldots \ldots \ldots . . \ldots \quad 50 \mathrm{ml}$ 
3.1.12. Reagente de DNS

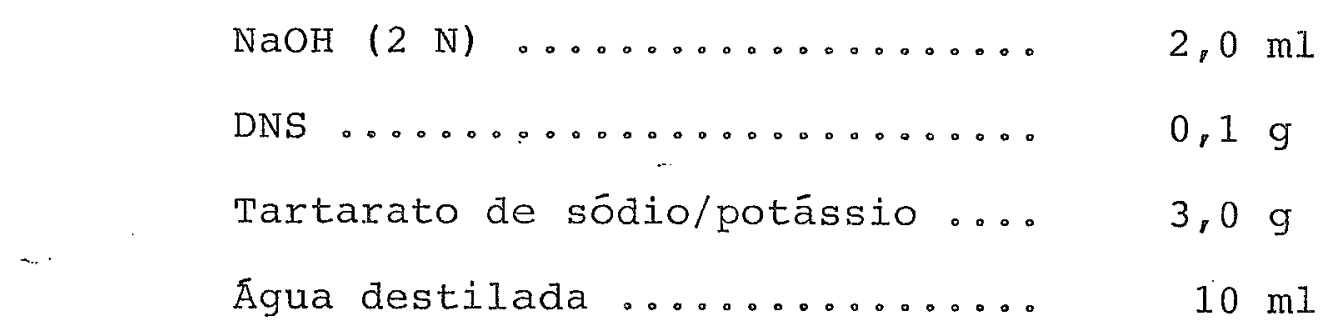

Em caso de precipitação, aqueceu-se em banho - maria a $50^{\circ} \mathrm{C}$.

3.1.13.Solução de Fixador de Helley

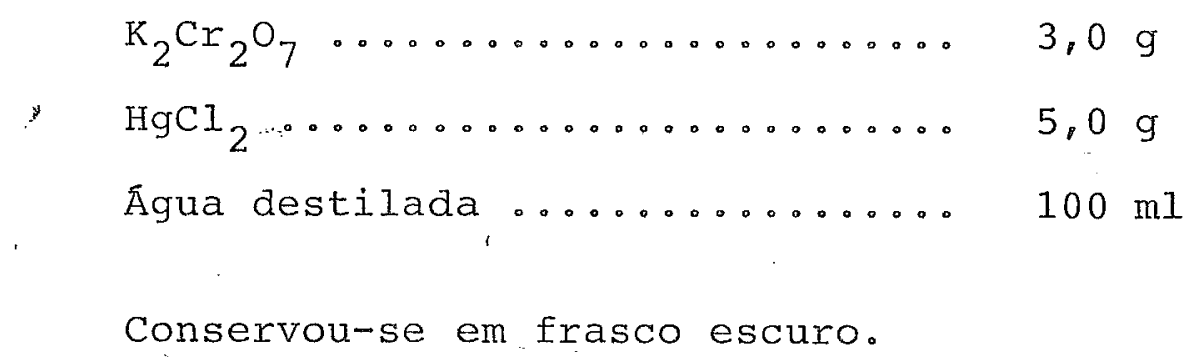

Conservou-se em frasco escuro.

\subsubsection{Formol neutro}

1 parte de carbonato de cálcio/3 partes de formalina, com agitação esporädica durante dez dias. 


\subsubsection{Tampão fosfato ${ }$ pH 6,9}

- Solução A

$$
\begin{aligned}
& \mathrm{NaH}_{2} \mathrm{PO}_{4} \ldots \ldots \ldots \ldots \ldots \ldots \ldots \ldots \ldots \ldots \ldots \ldots \ldots \ldots \ldots, 8 \mathrm{~g} \\
& \text { Água destilada .............. } 1000 \mathrm{ml}
\end{aligned}
$$

- Solução B

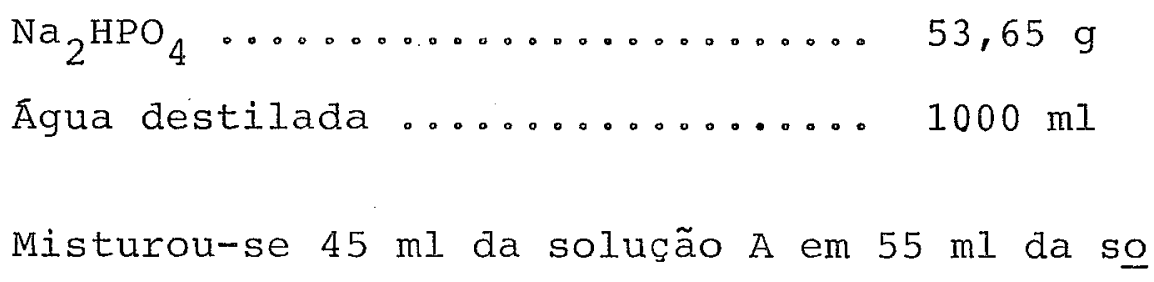

lução B e acertou-se o volume para $100 \mathrm{ml}$ com ăgua destilada. Conservou-se a $4^{\circ} \mathrm{C}$.

\subsubsection{Solução de albumina}

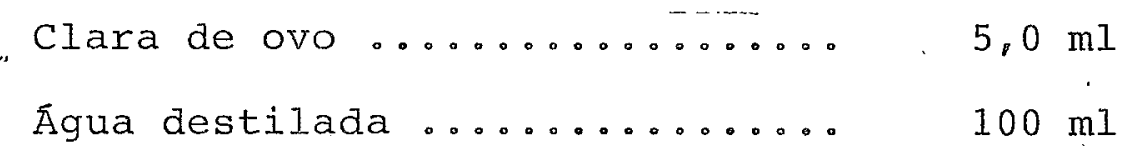

Filtrou-se e conservou-se em frasco escuro a $4^{\circ} \mathrm{C}$

3.1.17. Solução padrão de pNPG (para nitrofenil B-Dglico piracosideo) 
sol. tampão de acetato de sódio

$50 \mathrm{mM} \mathrm{pH} 5,0 \ldots \ldots \ldots \ldots \ldots \ldots \ldots \ldots$

\subsection{Métodos}

\subsubsection{Coleta e isolamento}

Foram coletadas amostras de madeiras, folhedos em decomposição e de visceração em larvas e insetos adul tos de isópteros e coleópteros, que se alimentam de madeira. O isolamento foi feito em meio especifico (MM) (AARONSON, 1970), e apresentando como única fonte de carbono a celulose (tiras de papel de filtro, ou celulose pulverizada). o local da coleta foi a mata da Fazenda São José - Rio Claro, SP, éa reserva da EMBRAPA/CPATU, Belém, Pará. Os fungos, larvas e insetos foram colocados em frascos de vidro esteriliza dos, tampados e levados ao laboratório, onde as larvas e os insetos foram tratados, dessecados e suas vísceras foram res suspendidas em solução salina; posteriormente, foram inocula das no meio acima citado. Incubou-se a $28^{\circ} \mathrm{C}$ por sete dias. Fez-se repicagens sucessivas para purificação das linhagens celuloliticas. Após purificação, elas foram transferidas pa ra MC (PONTECORVO, 1953), para sua conservação. Sua manuten ção foi feita em MC a $4^{\circ} \mathrm{C}$ e temperatura ambiente e repicadas a cada 6 meses. 
3.2.2. Dosagem comparativa da producão de celulases totais

Para uma dosagem prévia da capacidade de hidrólise dos microrganismos isolados, utilizou-se a técnica de produção de halo de degradação da celulose descrita por HANKIN et alii (1975); para tanto usou-se o $\mathbb{I}$. reesei $Q M$ 9414 como padrão. Os isolados foram inoculados em tubos con tendo o meio de celulose ácida,"incubados a $28^{\circ} \mathrm{C}$ e as leituras foram feitas com 5, 7, 9, 11 e 15 dias. Os halos de hidrölise foram medidos em profundidade (cm) em tubos $15 \times 2,5$ $\mathrm{cm}$ 。

3.2.3. Estudo da biologia dos microrganismos isolados

.3.2.3.1. Temperatura de cultivo e taxa de crescimento

Ensaiou-se no presente trabalho, três tempera turas $\left(28,37\right.$ e $\left.44^{\circ} \mathrm{C}\right)$ para se buscar a temperatura ideal de crescimento. Mediu-se os tamanhos das colōnias em cm com 3. 5 e 7 dias. 


\subsubsection{Meio de cultura}

A capacidade de crescimento e produção de coIônias, foram ensaiadas nos meios: MC: (PONTECORVÒ, 1953) mo dificado e MM (AARONSON, 1970). Utilizando-se diluições dos esporos para se obter colônias isoladas. Foi utilizado redu tor de crescimento, como citrato de sódio nas concentrações de 5,$10 ; 15$ e $20 \mathrm{mM}$.

\subsubsection{Produção de esporos}

Foram feitas contagens do nümero de esporos. Tomou-se amostras de 4 diferentes pontos da placa com auxilio de um mostrador padrão e diluiu-se 10 mo de salina ou Tween 80. Fez-se contagem em Camara de Neubauer. Com isto, estimou-se o número de esporos produzidos por ml, cia suspensão para cada um dos isolados e para os diferentes meios (MC e MM) .

\section{2 .3 .4 . Números de nücleos por esporos}

Atravēs de coloração especificica para nücleos (ROBINOW \& CATEN, 1969, modificado) (PAES DE BARROS, 1977) pode-se estimar o nümero de núcleos por esporos. A técnica consistiu-se em: fixar os esporos sobre a laminula com auxilio de albumina e chama. Apōs, deixou-se esta lamínula em uma solução de Helley $(5 \mathrm{ml})$ acrescida de $0,3 \mathrm{ml}$ de formol neutro por 15 minutos. Apōs 
este periodo colocou-se a laminula em álcool 70\% por alguns minutos, retirou-se e submeteu-se os esporos a hidrólise em ácido cloridrico $1 \mathrm{~N}$ a $63^{\circ} \mathrm{C}$ por aproximadamente 20 minutos. A seguir, lavou-se a laminula duas vezes em água destilada e coloriu-se com $5 \mathrm{ml}$ de solução fosfato, pH 6,9 e 9 gotas de Giensa, durante 30 minutos. A laminula foi lavada novamente em solução fosfato pH 6,9. Colocou-se a lamínula sobre a lâa mina e observou com imersão; com isto pode-se determinar e observar os núcleos em cada esporo.

\subsubsection{Dosagem da atividade das enzimas endoglucana- se exoglucanase e $\beta-g$ licosidases \\ 3.2.4.1. Obtenção do extrato enzimático}

Em erlenmeyers de $125 \mathrm{ml}$, contendo $5 \mathrm{ml}$ de água de torneira e $5 \mathrm{~g}$ de farelo de trigo, foi inoculada uma suspensão de $10^{7}$ esporos/ml $(3 \mathrm{ml})$ mantidos para crescer a $28^{\circ} \mathrm{C}$ por 10 dias.

Após o crescimento adicionou-se $30 \mathrm{ml}$ de água. destilada esterilizada, gelada e colocou-se. em refrigerador por três horas a cerca de $4{ }^{\circ} \mathrm{C}$ : Filtrou-se asseticamente em lã de vidro e o filtrado foi usado como fonte de celulases. Este filtrado pode ser mantido no refrigerador, por um longo período. 
3.2.4.2. Avicelase (atividade exoglucanase ou 1,4 B-glucan celobiohidrolase - $\mathrm{IC}$. 3.2 .1 .1

Foi colocado em tubos, 2,5 ml de tampão aceta to de sódio $50 \mathrm{mM}, \mathrm{pH} 5,0$, acrescentando-se $50 \mathrm{mg}$ de Avicel e incubou-se por três minutos a $50^{\circ} \mathrm{C}$ para equilíbrio da temperatura. Posteriormente, colocou-se 2,5 ml do filtrado da cultura de cada um dos fungos isolados, agitou-se e colocou- se na estufa a $28^{\circ} \mathrm{C}$ retirou-se amostras de $1 \mathrm{ml}$ nos tempos de zero, 30 e 60 minutos e colocou-se em tubos de centrifuga clinica contendo $1 \mathrm{ml}$ de reagente de DNS, centrifugou-se a $5000 \mathrm{rpm}$, transferiu-se o sobrenadante para outro tubo e colocou-se en̆ banho-maria fervente por 5 minutos, resfriou-se e colocou-se $10 \mathrm{ml}$ de água destilada, fez-se leitura a 540 nm em colorímetro fotoelétrico B340 Micronal, onde foi dosada a glicose produzida e o valor estimado frente a um padrão de glicose $(5.0 \mathrm{mg} / 50 \mathrm{ml})$. Os resultados foram fornecidos em atividade $\mu \mathrm{mol} / \mathrm{min} / \mathrm{ml}$.

3.2.4.3. Carboximetilcelulases (atividade endoglucanase ou $1,4 \quad \beta$-glucan glucanohidrolase. EC 3.2.1.

o procedimento foi similar ao da Avicelase, a 
penas com o substrato Carboximetil celulose. o resultado foi dado pela atividade em $\mathrm{mol} / \mathrm{min} / \mathrm{ml}$.

\subsubsection{B-glicosidase}

Ressuspendeu-se $1 \mathrm{mg}$ de pNPG em $1 \mathrm{ml}$ de tampão acetado de södio $50 \mathrm{nM}$, pH 5,0, colocou-se em um tubo $0,5 \mathrm{ml}$ de pNPG na concentração acima e 0,5 ml do filtrado do cultivo, fez-se a reação nos tempos 30 e 60 minutos, paralizou-se a reação com tetra borato de sódio saturado $(2 \mathrm{ml})$ e fez-se a leitura em $412 \mathrm{~nm}$.

Paralelamente, fez-se uma curva padrão de paranitrofenil (pNP) com concentrações conhecidas. Tomou-se $13,9 \mathrm{mg}$ de pNP e diluiu-se em $100 \mathrm{ml}$ de tampão acetado de só dio $50 \mathrm{nM}, \mathrm{pH}$ 5,0, fez-se uma amostragem desta solução com $10,20,30,40,50,60,70,80,90$ e $100 \mathrm{ml}$, completou-se o volume com $0,5 \mathrm{ml}$ de água destilada e paralisou-se a reação com 2,0 ml de tetraborato de sódio, fez-se a leitura a 412 nm em absorbāncia. Após a calibração da reta, fez-se ós cāl culos dos resultados obtidos, fornecidos em $\mu \mathrm{mol} / \mathrm{min} / \mathrm{ml}$ de paranitrofenil. 
4. RESULTADOS

4.1. ORIGEM DO MATERIAL E CARACTERIZACÃO MORFOLÓGICA DOS ISOLADOS

Utilizando o meio de AARONSON (1970), foi pos sivel o isolamento de vinte tipos de fungos; estes, acham-se listados na Tabela 1, onde também pode se verificar a origem dos isolados e" locais de coleta.

4.2. DOSAGEl COMPARATIVA DA PRODUCÁO DE CELULOSES TOTAIS

o meio utilizado neste ensaio foi o meio de celulose ácida modificado e os valores observados de halo de degradação em profundidade, podem ser vistos na Tabela 2. 
TABEIA. 1. Origem dos fungos isolados, local de coleta e aspectos morfológicos dos isolados.

\begin{tabular}{|c|c|c|c|}
\hline NO. & Origem dos isolados & $\begin{array}{l}\text { Local de } \\
\text { coleta }\end{array}$ & $\begin{array}{l}\text { Caracteristica } \\
\text { morfológicạ }\end{array}$ \\
\hline 1 & Coleōptero adulto & CPATU-Belēm & cinza,bordas'brancas \\
\hline 2 & Madeira seca & CPATU-Belém & branco cotonoso \\
\hline 3 & Coleóptero larva. & CPATU-Belém & branco acinzentado. \\
\hline 4 & Coleóptero larva & CPATU-Belém & cinza esverdeado \\
\hline 5 & Isóptero adulto & CPATU-Belēm & verde \\
\hline 6 & Madeira decomposição & CPATU-Belëm & mostarda \\
\hline 7 & Coleóptero larva & CPATU-Belēm & verde \\
\hline 8 & Isōptero larva & CPATU-Belém & cinza \\
\hline 9 & Madeirá seca & CPATU-Belém & branco \\
\hline 10 & Isóptero adulto & CPATU-Belēm & amarelo \\
\hline 11 & Coleóptero adulto & CPATU-Belém & cinza \\
\hline 12 & Coleōptero larva & CPATU-Belém & cinza \\
\hline 13 & Coleóptero larva & MATA UNESP (RC) & verde \\
\hline 14 & Coleóptero larva & MATA UNESP (RC) & marrom claro \\
\hline 15 & Coleóptero larva & MATA UNESP (RC) & branco esverdeado \\
\hline 16 & Coleóptero larva & MATA UNESP (RC) & chumbo \\
\hline 17 & Madeira em decomposição & MATA UNESP (RC) & preto \\
\hline 18 & Madeira em decomposição : & MATA UNESP (RC) & esverdeado \\
\hline 19 & Madeira èm decomposição & MATA UNESP (RC) & verde \\
\hline 20 & Madeira em decomposição & MATA UNESP (RC) & preto \\
\hline
\end{tabular}


TABELA 2. Medidas do halo de degradação por profundidades em tubos, utilizando-se o meio de celulose ácida modi ficado.

\begin{tabular}{|c|c|c|c|c|c|}
\hline NO & 5o dia & 70 dia & 90 dia & 110 dia & 150 dia \\
\hline 1 & 0,6 & 0,9 & 0,9 & 1,0 & 1,1 \\
\hline 2 & 0,0 & 0,6 & 0,6 & 0,6 & 0,8 \\
\hline 3 & 0,8 & 1,2 & 1,2 & 1,4 & 1,6 \\
\hline 4 & 0,4 & 0,7 & 0,9 & 1,0 & 1,0 \\
\hline 5 & 0,9 & 1,0 & 1,0 & 1,4 & 1,8 \\
\hline 6 & 0,9 & 1,1 & 1,3 & 1,4 & 2,0 \\
\hline 7 & 1,0 & 1,1 & 1,4 & 1,5 & 2,0 \\
\hline 8 & 0,8 & 1,0 & 1,2 & 1,4 & 1,6 \\
\hline 9 & 0,0 & 0,7 & 0,9 & 1,0 & 1,0 \\
\hline 10 & 0,6 & 0,7 & 0,8 & 0,9 & 1,0 \\
\hline 11 & 0,4 & 0,8 & 1,0 & 1,3 & 1,5 \\
\hline 12 & 0,0 & 0,5 & 0,5 & 0,6 & 0,6 \\
\hline 13 & 0,8 & 1,1 & 1,1 & 1,5 & 1,8 \\
\hline 14 & 0,7 & 0,9 & 1,1 & 1,3 & 1,6 \\
\hline 15 & 0,6 & 0,9 & 1,0 & 1,1 & 1,3 \\
\hline 16 & 0,4 & 0,6 & 0,6 & $\ldots, 8$ & 1,1 \\
\hline 17 & 0,5 & 0,8 & 1,2 & 1,4 & 1,5 \\
\hline 18 & 0,7 & 1,0 & 1,2 & 1,5 & 1,7 \\
\hline 19 & 0,5 & 0,8 & 1,0 & 1,3 & 1,5 \\
\hline 20 & 0,6 & 0,9 & 1,1 & 1,3 & 1,5 \\
\hline \multicolumn{6}{|l|}{ T.reesei } \\
\hline (QM 941.4) & 1,0 & 1,2 & 1,5 & 1,6 & 1,9 \\
\hline
\end{tabular}

Trichoderma reesei (QM 9414) = padrão

Medidas em com (profundidade) (tubos $15 \times 2,5 \mathrm{~cm}$ ) 


\subsection{ENSAIO DO CRESCIMENTO DOS FUngOS EM DIFERENTES MEIOS E DIFERENTES TEMPERATURAS}

Com o objetivo de encontrar uma temperatura e meios ideais de crescimento, os isolados foram inoculados em placas de Petri, contendo Meio Completo (PONTEConVo, 1953) e Meio Mínimo (AARONSON, 1970) e incubados nas temperaturas de 28,37 e $44^{\circ} \mathrm{C}$, por nove dias. As Tabelas 3, 4, 5 apresentam os resultados obtidos neste ensaio relativos à medida do diâmetro das colônias em função do meio de cultura e tempera tura de incubação.

\subsection{PRODUCÃO DE ESPOROS}

Para observar a produção de esporos dos isola dos fez-se inoculação dos mesmos em placas de Petri contendo MC e MM e foram incubados em três temperaturas diferentes. Fez-se um tratamento estatístico através da análise de variância dos resultados das contagens segundo um delineamento experimental em parcelas subdivididas sobre blocos ao acaso. Estas análises podem ser vistas na Tabela 6 e 7 .

\subsection{Estudos CitTOLógicos}

Como auxiliar em estudos genéticos dos fun- 
TABELA 3. Medida do diâmetro das colônias no 5\%, 7\% e $9 \%$ dias em Meio Mínimo (AARONSON, 1970) e Meio Comple to (PONTECORVO, 1953), incubados a $28^{\circ} \mathrm{C}$.

\begin{tabular}{|c|c|c|c|c|c|c|c|}
\hline \multirow[t]{2}{*}{ NO } & \multicolumn{3}{|c|}{ Meio MInimo } & \multicolumn{4}{|c|}{ Meio Completo } \\
\hline & $5 \%$ dia & 7\% dia & 90 dia & 5ㅇ dia & 7: dia & 90 & dia \\
\hline 1 & 5,0 & $\mathrm{TP}$ & $\mathrm{TP}$ & $\mathrm{TP}$ & $\mathrm{TP}$ & & $\mathrm{TP}$ \\
\hline 2 & 1,5 & 3,0 & 3,0 & $\mathrm{TP}$ & $\mathrm{TP}$ & & $T P$ \\
\hline 3 & 0,5 & $\mathrm{TP}$ & $\mathrm{TP}$ & $\mathrm{TP}$ & $\mathrm{TP}$ & & $\mathrm{TP}$ \\
\hline 4 & 2,0 & 3,0 & 5,0 & 2,2 & 3,0 & & 3,0 \\
\hline 5 & 0,2 & 6,0 & 6,0 & $\mathrm{TP}$ & $\mathrm{TP}$ & & $\mathrm{TP}$ \\
\hline 6 & 0,3 & 4,0 & 5,0 & 5,5 & $\mathrm{TP}$ & & $\mathrm{TP}$ \\
\hline 7 & $\mathrm{TP}$ & $\mathrm{TP}$ & $\mathrm{TP}$ & $\mathrm{TP}$ & $\mathrm{TP}$ & & $\mathrm{TP}$ \\
\hline 8 & 0,5 & $\mathrm{TP}$ & $\mathrm{TP}$ & $2 ; 0$ & 3,0 & & 4,0 \\
\hline 9 & 1,5 & 3,0 & 4,0 & 2,8 & 4,0 & & 5,0 \\
\hline 10 & $\mathrm{TP}$ & $\mathrm{TP}$ & $\mathrm{TP}$ & 1,5 & 1,5 & & 1,5 \\
\hline 11 & 0,4 & $T P$ & TP & $\mathrm{TP}$ & $\mathrm{TP}$ & & $\mathrm{TP}$ \\
\hline 12 & 0,5 & 1,0 & 1,0 & 1,7 & 2,0 & & 3,5 \\
\hline 13 & 0,3 & $\mathrm{TP}$ & $\mathrm{TP}$ & $\mathrm{TP}$ & $\mathrm{TP}$ & & $\mathrm{TP}$ \\
\hline 14 & 0,2 & 2,0 & 2,0 & 7,0 & $\mathrm{TP}$ & & $\mathrm{TP}$ \\
\hline 15 & 0,4 & $\mathrm{TP}$ & $\mathrm{TP}$ & $\mathrm{TP}$ & $\mathrm{TP}$ & & $\mathrm{TP}$ \\
\hline 16 & 0,5 & 2,0 & 2,0 & 3,5 & $\mathrm{TP}$ & & $\mathrm{TP}$ \\
\hline 17 & $\mathrm{TP}$ & $\mathrm{TP}$ & $\mathrm{TP}$ & $\mathrm{TP}$ & $\mathrm{TP}$ & & $\mathrm{TP}$ \\
\hline 18 & $T P$ & $\mathrm{TP}$ & $\mathrm{TP}$ & $\mathrm{TP}$ & $\mathrm{TP}$ & & $\mathrm{TP}$ \\
\hline 19 & $\mathrm{TP}$ & $\mathrm{TP}$ & $\mathrm{TP}$ & $\mathrm{TP}$ & $\mathrm{TP}$ & & $\mathrm{TP}$ \\
\hline 20 & $\mathrm{TP}$ & $\mathrm{TP}$ & $\mathrm{TP}$ & $\mathrm{TP}$ & $\mathrm{TP}$ & & $\mathrm{TP}$ \\
\hline
\end{tabular}

Diâmetro da colônia em $\mathrm{cm}$ $\mathrm{TP}=$ Toda a Placa 
TABELA 4. Média do diâmetro das colônias, no 5\%, .7\% e 9 : dia em Meio Mínimo (AARONSON, 1970) e Meio Completo (PONTECORVO, 1953), incubados a $37^{\circ} \mathrm{C}$.

Nㅇ

$\frac{\text { Meio Minimo }}{5 \circ \text { dia } 70 \text { dia 9\% dia }}$

\section{Meio Completo}

58 dia 70 dia 90 dia

\begin{tabular}{|c|c|c|c|c|c|c|}
\hline 1 & 6,5 & 7,0 & 7,5 & 9,0 & $\mathrm{TP}$ & $\mathrm{TP}$ \\
\hline 2 & 1,0 & 3,0 & 3,0 & 3,5 & 6,5 & $\mathrm{TP}$ \\
\hline 3 & 0,4 & 6,0 & 6,0 & 6,5 & $\mathrm{TP}$ & $\mathrm{TP}$ \\
\hline 4 & 1,5 & 3,0 & 3,5 & 3,5 & $\mathrm{TP}$ & $T P$ \\
\hline 5 & 5,0 & 6,0 & 6,0 & 6,0 & $\mathrm{TP}$ & TP \\
\hline 6 & 1,2 & 2,0 & 4,0 & 2,8 & $\mathrm{TP}$ & $\mathrm{TP}$ \\
\hline 7 & 5,0 & 7,0 & 7,0 & 7,0 & $\mathrm{TP}$ & $\mathrm{TP}$ \\
\hline 8 & 1,0 & 7,0 & - & 1,3 & 2,0 & 2,0 \\
\hline 9 & 1,8 & 2,0 & 2,0 & 1,5 & 2,0 & 2,0 \\
\hline 10 & 1,5 & - & $\mathrm{TP}$ & 0,8 & 1,0 & - \\
\hline 11 & 5,0 & 6,0 & 6,0 & $\mathrm{TP}$ & $\mathrm{TP}$ & $\mathrm{TP}$ \\
\hline 12 & 0,2 & 0,5 & 1,0 & 0,5 & 1,0 & 1,0 \\
\hline 13 & 2,5 & 6,5 & 6,5 & 6,5 & $\mathrm{TP}$ & $\mathrm{TP}$ \\
\hline 14 & - & - & - & 0,7 & 2,0 & 3,0 \\
\hline 15 & 0,3 & 6,5 & 6,5 & 6,0 & 7,5 & 7,5 \\
\hline 16 & 0,3 & 2,0 & 2,5 & - & - & - \\
\hline 17 & 5,0 & 5,5 & 6,0 & 5,0 & 5,5 & 7,0 \\
\hline 18 & 4,5 & 5,0 & 5,5 & 5,0 & 6,0 & 7,0 \\
\hline 19 & 5,0 & 5,0 & 5,5 & 5,5 & 6,0 & 7,0 \\
\hline 20 & 5,0 & 5,5 & 6,0 & 6,0 & 6,5 & 8,0 \\
\hline
\end{tabular}

Diâmetro da colônia em cm

$\mathrm{TP}=$ Toda a Placa

- = não houve crescimento 
TABELA 5. Medida do diâmetro das colônias, no 5\%, 7\% e 9: dias, em Meio Minimo (AARONSON, 1970) e Meio Completo (PONTECORVO, 1953), incubados a $44^{\circ} \mathrm{C}$.

\begin{tabular}{|c|c|c|c|c|c|c|c|}
\hline \multirow{2}{*}{ NO } & \multicolumn{3}{|c|}{ Meio Mínimo } & \multicolumn{4}{|c|}{ Meio Completo } \\
\hline & 5: dia & 79 dia & 90 dia & 50 dia & 70 dia & $9 \circ$ & dia \\
\hline 1 & - & - & - & - & - & & - \\
\hline 2 & $\mathrm{TP}$ & $\mathrm{TP}$ & $\mathrm{TP}$ & 5,0 & $\mathrm{TP}$ & & $\mathrm{TP}$ \\
\hline 3 & 0,5 & 1,0 & - & - & - & & - \\
\hline 4 & 2,5 & - & - & 5,5 & $\mathrm{TP}$ & & $\mathrm{TP}$ \\
\hline 5 & - & - & - & - & - & & - \\
\hline 6 & 2,0 & 3,0 & 4,0 & - & - & & - \\
\hline 7 & 0,5 & - & - & - & 1,0 & & $\mathrm{TP}$ \\
\hline 8 & $2 ; 0$ & 3,0 & 3,0 & 1,0 & 2,0 & & 3,0 \\
\hline 9 & - & - & - & - & - & & - \\
\hline 10 & - & - & - & - & - & & - \\
\hline 11 & - & - & - & - & - & & - \\
\hline 12 & - & - & - & - & - & & - \\
\hline 13 & - & - & - & - & - & & - \\
\hline 14 & - & - & - & - & - & & - \\
\hline 15 & 0,2 & - & - & - & - & & - \\
\hline 16 & 0,2 & - & - & - & - & & - \\
\hline 17 & - & - & - & - & - & & - \\
\hline 18 & - & - & - & - & - & & - \\
\hline 19 & - & - & - & - & - & & - \\
\hline 20 & - & - & - & - & - & & - \\
\hline
\end{tabular}

Diâmetro da colônia em cm $\mathrm{TP}=$ Toda a Placa

- = não houve crescimento 
TABELA 6. Produção de esporos em Meio Mínimo (AARONSON,1970) incubados a $28^{\circ}$ e $37^{\circ} \mathrm{C}$.

\begin{tabular}{|c|c|c|c|}
\hline \multirow[t]{2}{*}{ Linhagens } & \multirow{2}{*}{ Temperatura } & \multicolumn{2}{|c|}{ - Meio MInimo } \\
\hline & & $\begin{array}{l}\text { No esporos } \\
\left(x \quad 10^{6}\right)\end{array}$ & $\begin{array}{c}\text { No esporos } \\
\left(\mathrm{x} 10^{6}\right)\end{array}$ \\
\hline 1 & $\begin{array}{l}28 \\
37\end{array}$ & $\begin{array}{l}108 \\
174\end{array}$ & $\begin{array}{l}106 \\
170\end{array}$ \\
\hline 2 & $\begin{array}{l}28 \\
37\end{array}$ & $\begin{array}{r}164 \\
55\end{array}$ & $\begin{array}{r}160 \\
50\end{array}$ \\
\hline 3 & $\begin{array}{l}28 \\
37\end{array}$ & $\begin{array}{r}76 \\
3\end{array}$ & $\begin{array}{r}73 \\
1\end{array}$ \\
\hline 5 & $\begin{array}{l}28 \\
37\end{array}$ & $\begin{array}{r}291 \\
17\end{array}$ & $\begin{array}{l}29 \\
15\end{array}$ \\
\hline 6 & $\begin{array}{l}28 \\
37\end{array}$ & $\begin{array}{r}44 \\
5\end{array}$ & $\begin{array}{r}48 \\
8\end{array}$ \\
\hline 8 & $\begin{array}{l}28 \\
37\end{array}$ & $\begin{array}{l}190 \\
150\end{array}$ & $\begin{array}{l}190 \\
140\end{array}$ \\
\hline 9 & $\begin{array}{l}28 \\
37\end{array}$ & $\begin{array}{l}48 \\
67\end{array}$ & $\begin{array}{l}50 \\
60\end{array}$ \\
\hline 11 & $\begin{array}{l}28 \\
37\end{array}$ & $\begin{array}{l}134 \\
137\end{array}$ & $\begin{array}{l}134 \\
130\end{array}$ \\
\hline 13 & $\begin{array}{l}28 \\
37\end{array}$ & $\begin{array}{r}200 \\
29\end{array}$ & $\begin{array}{r}202 \\
20\end{array}$ \\
\hline 16 & $\begin{array}{l}28 \\
37\end{array}$ & $\begin{array}{r}192 \\
40\end{array}$ & $\begin{array}{r}188 \\
45\end{array}$ \\
\hline 17 & $\begin{array}{l}29 \\
37\end{array}$ & $\begin{array}{r}9 \\
30\end{array}$ & $\begin{array}{l}10 \\
35\end{array}$ \\
\hline 18 & $\begin{array}{l}28 \\
37\end{array}$ & $\begin{array}{l}300 \\
300\end{array}$ & $\begin{array}{l}350 \\
300\end{array}$ \\
\hline 19 & $\begin{array}{l}28 \\
37\end{array}$ & $\begin{array}{l}200 \\
150\end{array}$ & $\begin{array}{l}250 \\
160\end{array}$ \\
\hline 20 & $\begin{array}{l}28 \\
37\end{array}$ & $\begin{array}{l}72 \\
80\end{array}$ & $\begin{array}{l}60 \\
70\end{array}$ \\
\hline
\end{tabular}


TABELA 6. (continuação)

Split-plot

\begin{tabular}{lcrrr}
\hline CV & GI & SQ & QM & F \\
\hline Blocos & 1 & 795,0179 & 795,0179 & 0,5621 \\
Tratamentos & 13 & 308418,3036 & 23724,4849 & $16,7730 * *$ \\
Residuo (A) & 13 & 18387,7321 & 1414,4409 & \\
\hline & 137 & 327601,0536 & & $14,76 * *$ \\
(Parcelas) & 1 & 36872,4465 & 19018,2857 & $14,75 *$ \\
Temp. & 13 & 68172,3035 & 20291,6126 & 15, \\
T x Trat. & 14 & 18039,7500 & 1288,5536 & \\
Residuo (B) & & & & \\
\hline
\end{tabular}

$* *$ significantes 
TABELA 7. Produção de esporos em Meio Completo (PONTECoRvo, $1953)$ incubados a $23^{\circ} \mathrm{C}$ e $37^{\circ} \mathrm{C}$.

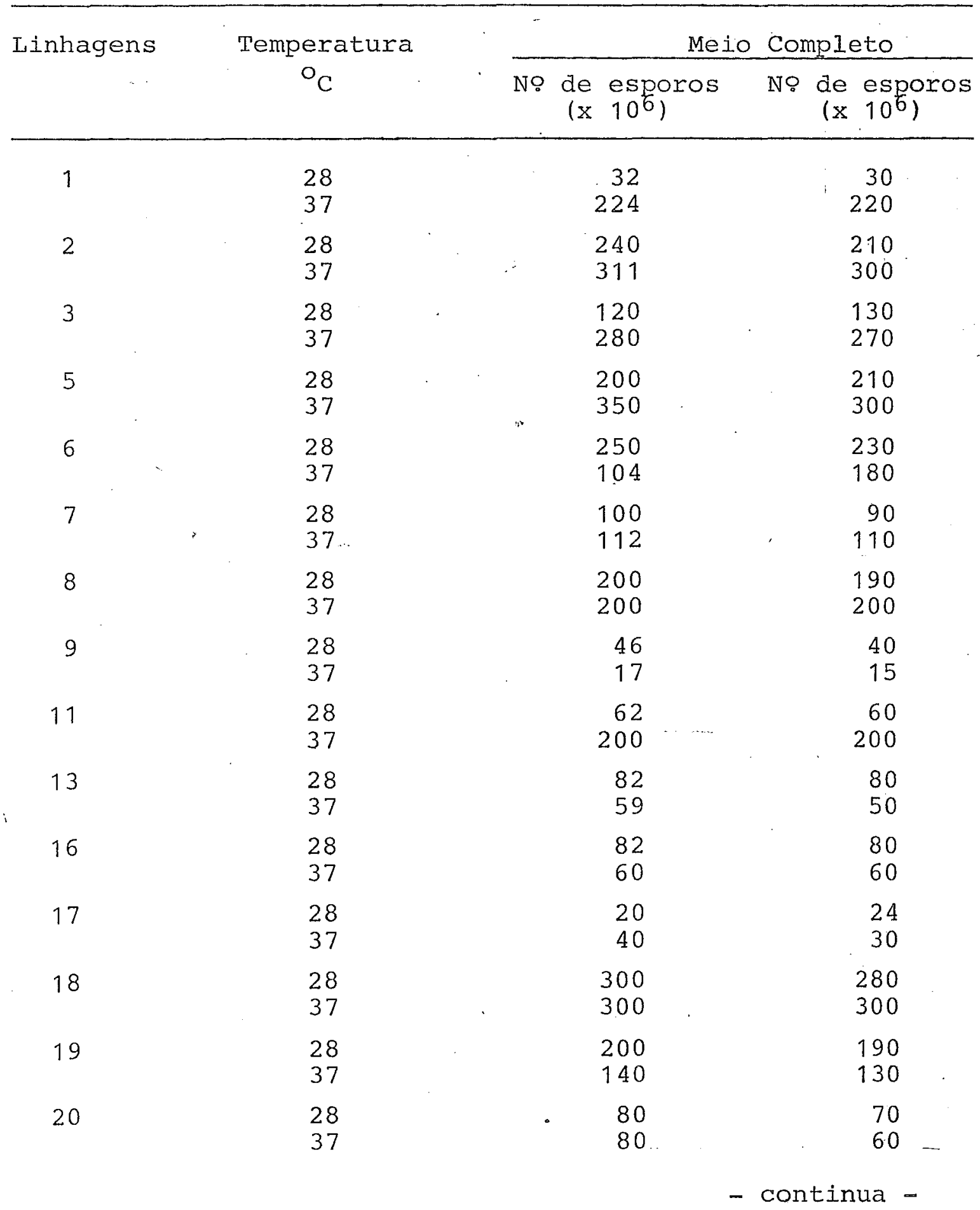


TABEL.A 7. (continuação)

Split-plot

\begin{tabular}{crrrr}
\hline CV & GL & \multicolumn{1}{c}{ SQ } & \multicolumn{1}{c}{ QM } & \multicolumn{1}{c}{$F$} \\
\hline Blocos & 1 & 385,0660 & 385,0660 & 3,06 \\
Tratamentos & 14 & 422359,8330 & 30168,5595 & $238,43 * *$ \\
Residuo (A) & 14 & 1771,4340 & 126,5310 & \\
\hline (Parcelas) & 29 & 424516,3330 & & \\
Temp. (T) & 1 & 15811,2660 & 15811,2660 & $69,72 * *$ \\
T x Trat. & 14 & 99022,2360 & 7073,0167 & $31,19 * *$ \\
Residuo (B) & 15 & 3628,5000 & 226,7813 & \\
\hline Total & 60 & 542978,3330 & & \\
\hline
\end{tabular}

** = significantes. 
gos, foram feitas determinações do número de núcleos por esporos, através de coloração dos mesmos. Os resultados podem ser observados na Tabela 8 .

\subsection{DOSAGEM DA ATIYIDADE ENZIMÁTICA}

Por se tratar basicamente de três enzimas envolvidas no processo de degradação da celulose, as mesmas foram dosadas separadamente, utilizando-se para cada uma delas substrato especifico. A atividade foi estimada " pela quantidade de glicose produzida" na reação em 60 minutos e os resultados foram dados em $\mu \mathrm{mol}$ de glicose/minuto/ml e estão listadós ná Tabela 9 para $C_{1}$ (Avicel), na Tabela 10 para $C_{x}$ (CMG $_{\text {ase) }}$ e Tabela 11 para $\beta$-glicosidade (pIPG). 
TABELA 8. Estudos citológicos dos isolados através de colora ção de núcleos.

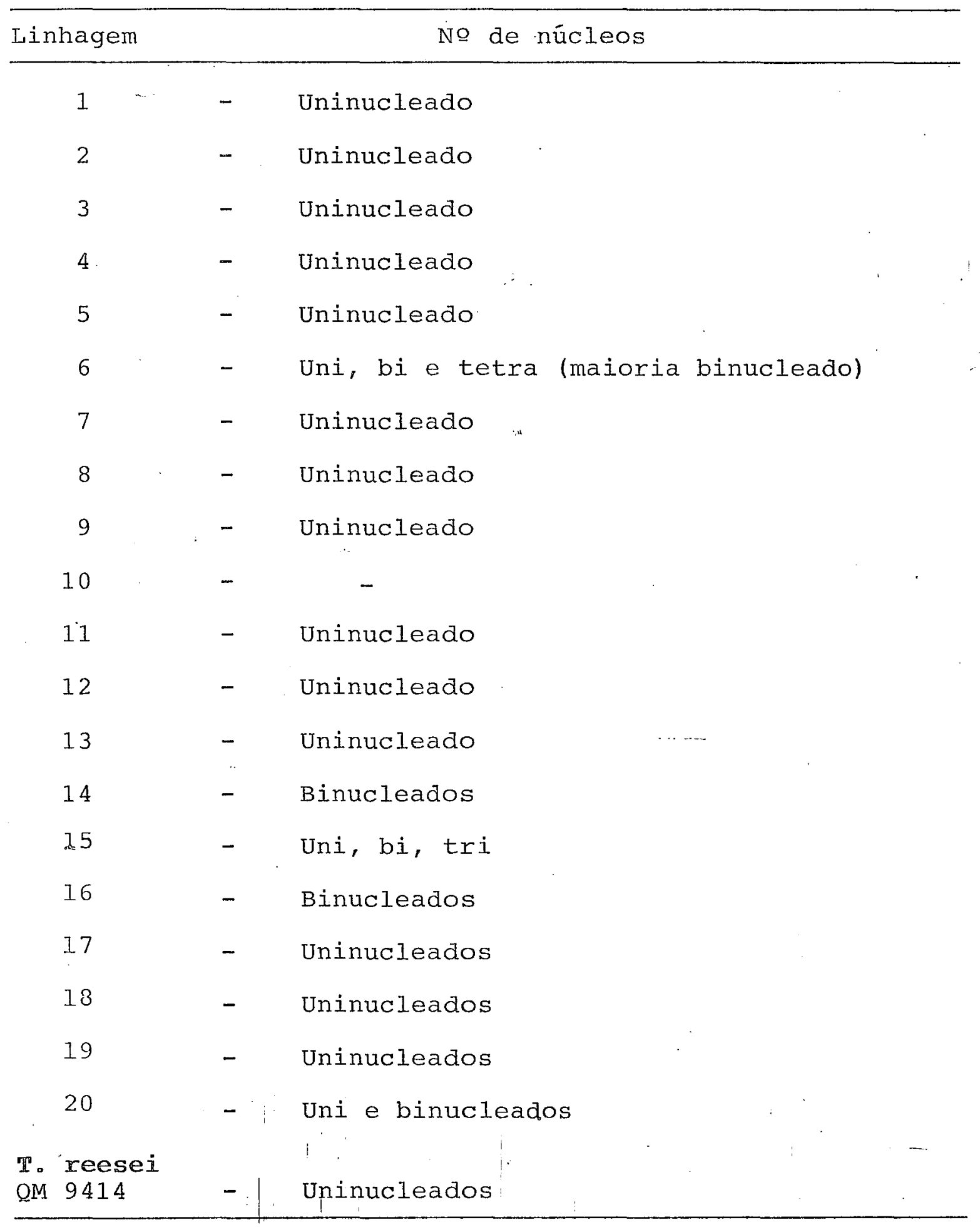


TABELA 9. Dosagem da atividade de exoglucanase $\left(\mathrm{C}_{1}\right)$ frente ao substrato Avicel, unidade de atividade/mg total. de proteina.em 2 experimentos separados.

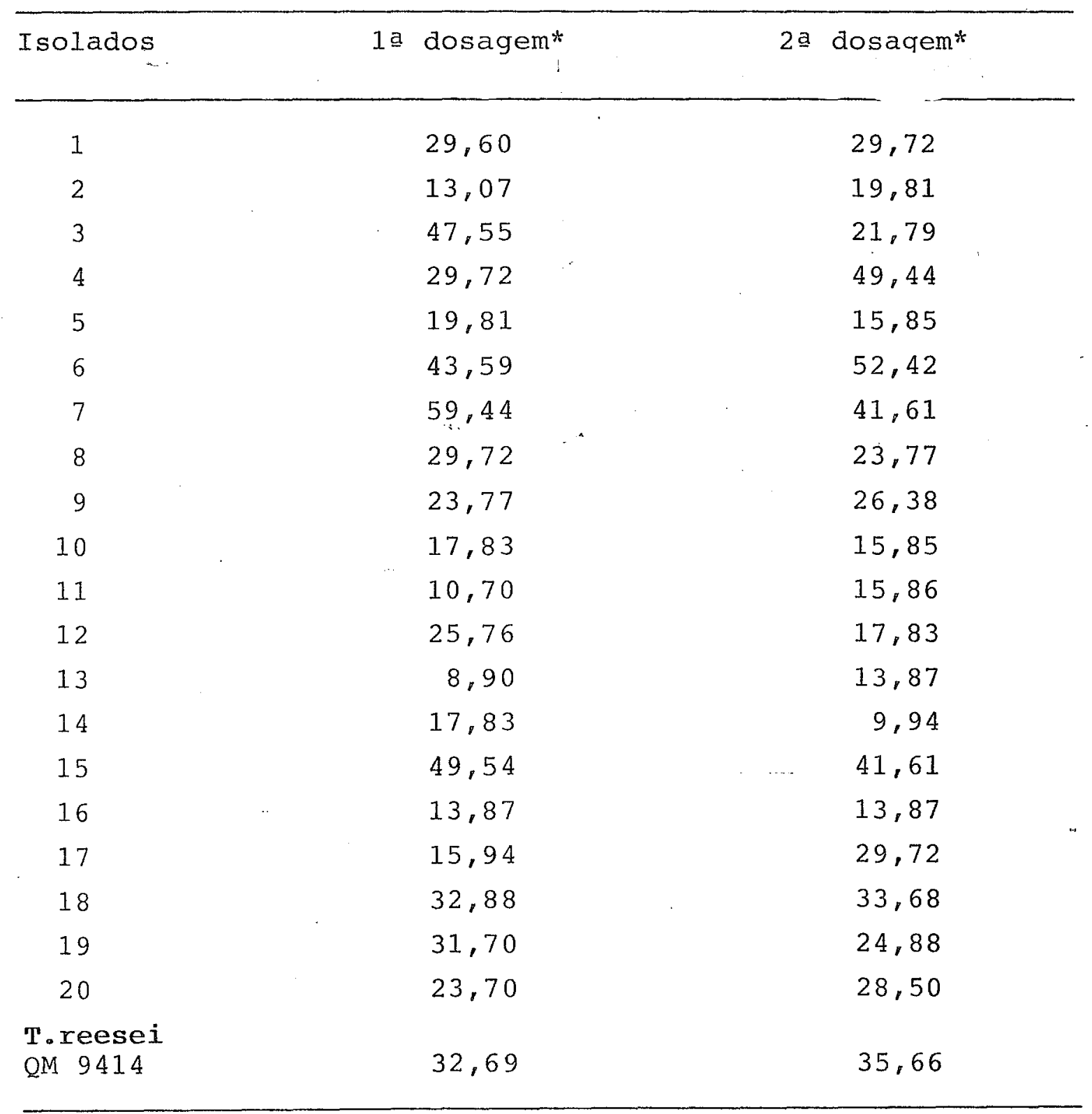

* : $\mu \mathrm{mol}$ de glicose $/ \mathrm{min} / \mathrm{ml}$ : tempo total de reação 60 minutos 
TABELA 10. Dosagem da atividade enzimática (endoglucanase) $\left(C_{x}\right)$ frente ao substrato carboximetil celulose (unidade de atividade/mg total de proteina).

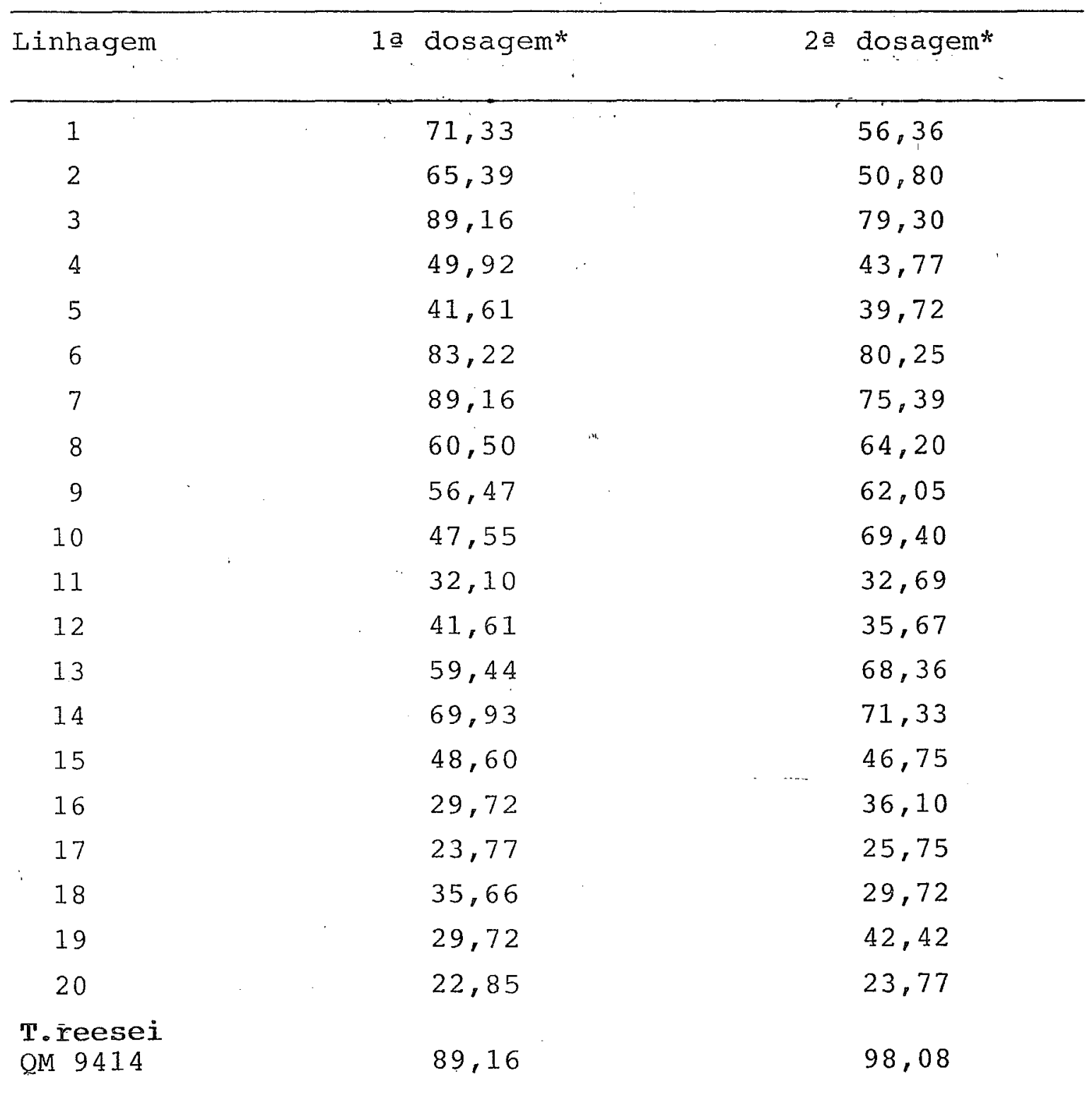

* : umol de glicose/min/ml 
TABELA 11. Atividade de $\beta-g l i c o s i d a s e$ frente ao substrato pNPG expressa em $\mu m o l$ de pNP formado/ml de prote na/minuto.

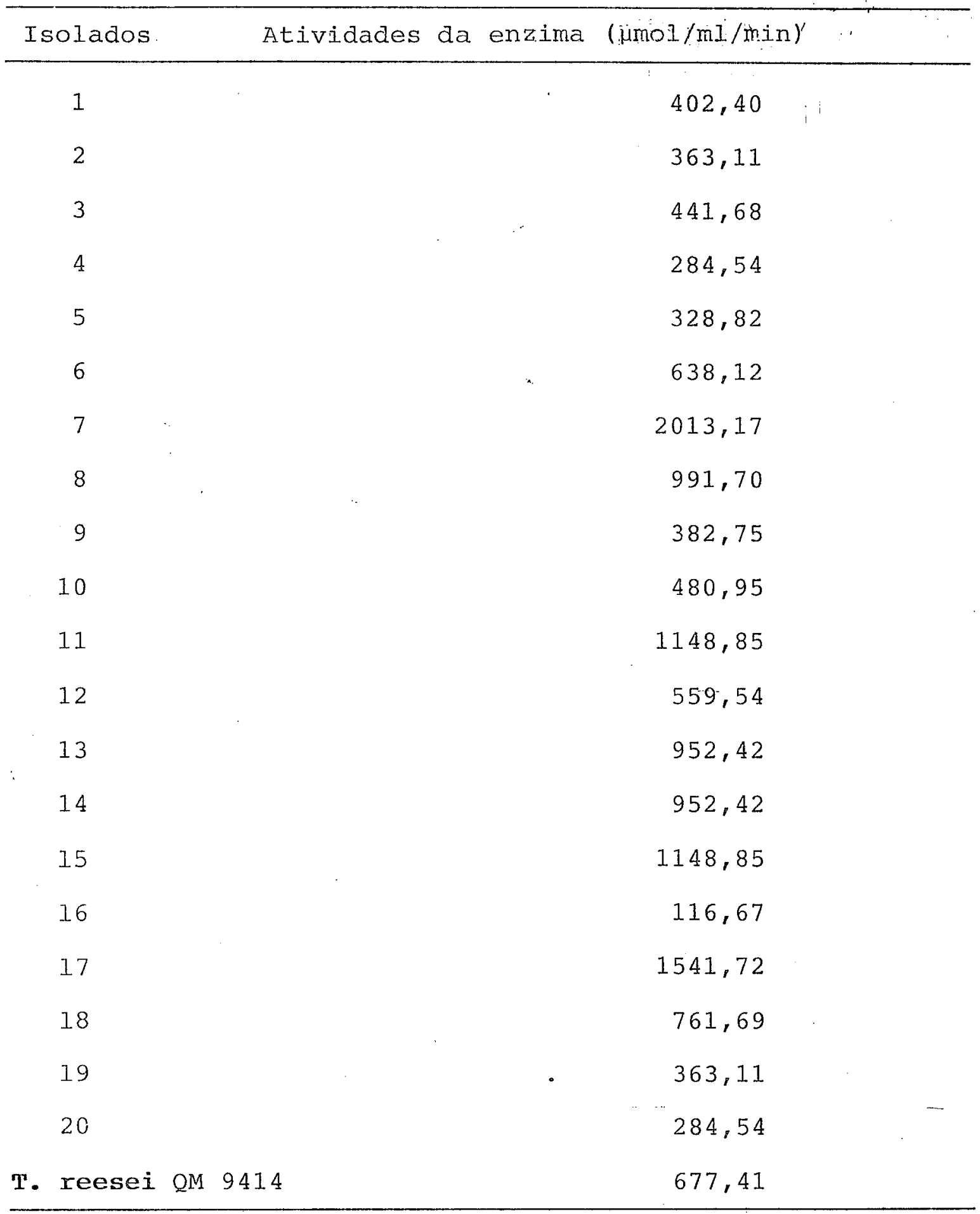




\section{DISCUSSÃO}

Com o objetivo de isolar fungos celuloliticos, no presente trabalho tomou-se como campo de busca duas matas distintas, a primeira foi a mata da Fazenda são José Rio Claso, SP, a segunda uma mata do tipo tropical, CPATU-EMBRAPA, Belém, PA. Escolheram-se estas duas matas por serem distintas, bem determinadas caracteristicamente e para se limitar o campo de isolamento. Nesses locais as amostras foram coletadas de madeiras e folhedos em decomposição, e de larvas e insetos (Isópteros e Coleópteros) que se alimentam de celulose.

Utilizando o meio de AARONSON (1970) o qual chamou-se de meio mínimo, isolaram-se 20 espécies de fungos que possuiam a característica básica, isto é, capacidadé de crescimento em meio de cultura, onde a única fonte de carbo- 
no era a celulose. Na Tabela 1 pode-se observar a origem dos isolados, o local de coleta e os aspectos morfológicos dos mesmos. Apesar da não classificação taxonomica dos isolados devido alguns parâmetros estarem sendo estudados, suge rem-se através de suas morfologias que os isolados de número 4, 5, 8, 13, 15, 18 e 19 pertencem ao gênero Trichoderma o de no 6 ao gênero Aspergillus e os de no 17 e 20 a espécie Aspergillus niger. Segundo alguns autores (RYU, 1980; GHOSE \& GHOSE, 1979), os fungos pertencentes a estes gêneros são os melhores produtores e os mais bem estudados.

Para se avaliar a" capacidade de produção das enzimas do complexo celulolitico dos 20 isolados, utilizou-se a espécie Trichoderma reesei QM 9414, como padrão, e a técni ca de SMITH (1976) que em tubos de ensaio com meio apropriado, detecta a produção das enzimas pela difusão no meio de cultura contendo celulose como única fonte de carbono.

Neste ensaio poảe-se observar que com 7 dias de incubação os isolados de no 3, 5, 6, 7, 8, 13 e 18 apresentaram halos de degradação da celulose iguais ou semelhantes ao paarrão (Tabela 2) e que no 15: dia os isolados de no 6 e 7 apresentaram halos de degradação maiores que o padrão, enquan to que os isolados de nos $5,8,13,14,17$ se mostraram também bons produtores. Observou-se que alguns dos isolados não apresen taram resultados significativos nos 7 primeiros dias de incu 
bação, ruas que apresentaram uma boa produção com um maior tempo de crescimento. Pode-se inferir assim que a produção das enzimas celulolíticas pode variar com o tempo na sua excreção no meio de cultura (SMITH, 1976), ou com a atividade por se tratar de um complexo multienzimătico, agindo sinergisticamente sobre substratos especificos (SPREY \& LAMBERT, 1984. Outras técnicas de produção de halos de hidrólises em placas (HEDGER, 1982) podem ser utilizadas para a caracte rização de microrganismos celulolíticos, quando estes apresentam um crescimento colonial bem definido sem espelhamento pelas placas. Para os 20 isolados não foi possivel utilizar a técnica de halos em placas, pois drogas inibidoras de cres cimento atuam diferentemente nos mesmos; no presente trabatho utilizou-se citrato de sódio como redutor do crescimento em várias concentrações; entretanto, alguns dos isolados não apresentaram crescimento reduzido mesmo nas mais altas concentrações, o que dificultou a técnica da medida de halos formados.

Os resultados indicam assim que mesmo com -um pequeno número de fungos celulolíticos isolados há um grande potencial para a obtenção de espécies celulolíticas que se comparam ou mesmo podem ser superiores a linhagem tradicionalmente usada como o $\mathbf{T}$. reesei. . 
A definição de meios específicos para o crescimentọo e temperatura ótima dos isolados foram ensaiados. Para ó melhoramento genético é importante que se defina um meio minimo principalmente para permitir o isolamento de mutantes auxotróficos como marcadores genéticos; assim, utilizou-se meio completo (PONTECORVO, 1953) e o meio minimo (AARONSON, 1970) e 3 temperaturas diferentes ou seja 28,37 e $44^{\circ} \mathrm{C}$.

Pelos resultados obtidos e listados na Tabela 3,4 e 5 pode-se verificar que a maioria dos isolados é cons tituída por fungos mesófilos e apenas o isolado de no 2 comportou-se como um fungo termofilico. Alguns autores conside ram a termofilia como uma característica vantajosa pois estes apresentam maiores taxas de crescimento e sistema enzimá tico mais estável, pois a temperatura ótima para a atividade das enzimas do complexo celulolítico é aproximadamente $55^{\circ} \mathrm{C}$ (BELLANY, 1979). Entretanto, os ensaios no presente trabatho foram conduzidos a $28^{\circ} \mathrm{C}$, pois foi nesta temperatura que a maioria dos isolados apresentaram bom crescimento.

Considerando-se o crescimento nos dois meios de cultura utilizados, as diferentes temperaturas e a produção de esporos, pode-se verificar pelas análises estatisti ca de blocos ao acaso que as linhagens divergem entre si, o que sugere tratar de linhagens distintas. Os isolados $4 ; 7$, 
10, 12 e 14 não produziram esporos em meio mínimo e os isola dos 4, 10, 12 e 14 não apresentaram produção de esporos em meio completo (Tabela 6 e 7).

Para que as técnicas de mutação e recombinação possam ser aplicadas com sucesso, há necessidade de conhecimento citológico dos isolados, da forma de reproduça de microrganismos e de características outras desde coloração, até o tipo de colônias formadas (AZEVEDO, 1985) os resultados desta análise indicados na Tabela 8 demonstram que alguns dos isolados são uninucleados e que vai facilitar futuros estudos genéticos nos mesmos.

As atividades enzimáticas dos 20 isolados foram ensaiadas separadamente, para se avaliar cada enzima. pois verificou-se no caso do $\mathbf{T}$. reesei, que são encontradas elevados niveis de endoglucanase ou exoglucanase, mas a atividade especifica de B-glicosidase era muito baixa (WOOD, 1982), e para" uma hidrólise perfeita (completa) do material celulósico é necessário que os nîveis das três enzimas sejam balanceados pois o acúmulo de moléculas de celobiose ou celo triose, são inibidoras do processo de hidrólise. Dos isolados estudados alguns se mostraram promissores (Tabela 9, 10 e 11). E o caso por exemplo, do isolado 7 que possui atividade de exoglucanase e endoglucanase comparável ao To reesei e atividade de $\beta$-glicosidase bem maior que a de $\mathbf{T}$. reese 
Os resultados obtidos no presente trabalho, de monstra a importāncia do isolamento de novos microrganismos celuloliticos, pois existe uma alta probabilidade de se isolar microrganismos com capacidades favoráveis no próprio ambiente natural sem utilizar as técnicas de mutação ou manipu lação gênica; a exploração da variabilidade natural demonstra a potencialidade de obtënção de novas linhagens e espécies, possibilitando assim uma amplitude maior nos estudos de Melhoramento Genético das espécies celulolíticas. Linhagem como por exemplo. a de no 7 que apresenta alta quantidade. das 3 celulases, é uninucleada e produz um bom número de esporos, mostra-se igualmente favorável para a realização de programa de melhoramentos genēticos visando um incremento na produção de celulases de modo a torná-la competitiva e favorável para a produção de celulases. 


\section{COMCLUSÕES}

1. De vinte isolados obtidos alguns se mostraram semelhantes ou superiores a $\mathbf{T}$. reesei utilizado como padrão. Isto demonstra a alta variabilidade natural existente em fungos celuloliticos e a importāncia da busca de linhagem de habitats naturais.

2. Alguns isolados, especialmente o no 7 mostrou-se favorável para futuros estudos de genética e melhoramento na busca de mutantes que possam ser utilizados em processos industriais para a produção de celulases. 


\section{REFERÉnCIAS BIBLIOGRÁFICAS}

AARONSON; S., 1970. Experimental microbial ecology. Academic, Press. New York, USA. p. 80.

ADVANCES in Enzymatic Hydrolysis of Cellulose and Related material (Reese, E.T. etd.=. Pergamon, New York, 1963.

ANDREN, R.K., M. MANDELS \& J.E. MEDEIROS; 1976. Process biochem., 11, 2. Apud: Enzyme Microb. Technol., 1980, 2: $91-102$.

ANDREOTTI, R.E., M. MANDELS \& C. ROCHE, 1977. In: Bioconversion of cellulosic substances into energy, chemicals and microbial proteins (Ghose, T.K., ed.). Indian Institute of Technology Delhi, India, p. 249. 
AZEVEDO, J.L., 1985. Melhoramento genético de microrganismos e sua aplicação à hidrólise enzimática de biomassas. Anais do II Seminário de "Hidrólise Enzimática de Biomas sa". Maringá, PR, p. 93-106.

BERGHEN, L.E.R., L.G.PETTERSON \& U.B. AXIO FREDDRIKSSON, 1976. Are mechanism of enzymatic cellulase degradation. Eur. : Is of Biochem. 61: 621.

BERNAT, J.A. $\frac{1}{0}$ W. RZEDOWSKI, 1977。 Przem。Ferment. Rolny, 21, 11. Apud: Enzyme Microb. Technol。, 1980, 2: 99-102。 BRANDT, D., L. HONTZ \& M. MANDELS, 1973. Aiche Symp., 69, 127. Apud: Enzyme Microb. Technol., 1980. 2: 99-102。 BROWN, D.E. \& M.A. ZAINUUDEEN, 19.77. Growth kinetics and cellulase biosynthesis in the continuous aüture of Trichoderma viride. J. Biotechnol. Bioeng., 19, 7: 941-958. BROWN, D.E. \&.D.J. HALSTED, 1975. The effect of acid pH on the growth kinetics of Trichoderma viride. J. Biotechnøl. Bioeng., 17, : 8: 1199-1210.

CARVALHO, E.A., 1983. Sacarifjcação enzimática de materiais celulósicos I. "Apostilas do Seminārio de Biotecnologia"。 Lorena. SP. 
ERIKSSON, K.E., 1981. In: "Trends in the biology of fermentation for fuels and chemicals" (Hollander, A. eds.). pp. 19-32. Phenum Press, New York.

ERIKSSON, K.E.\& B. PETTERSSON, 1972. In: "Biodeterioration of Materials" (A.H. Walters and A.H. Hneck Van Der Plas, eds.). Vol. 2, p. 116. Applied Sciences Publischens Ltda. Iondon.

FERRER, A., Y. ALROY \& I. BRITO, 1977. Proc.Ann.Biochem。 Eng. Symp. 7,83 .

GALLO, B.J., R. ANDREOTTI, C. ROCHE, D. RYU \& M. MANDELS. In: Utilization of agricultural crop residues (Han, JoW. and Smith, S.K.) US Dept. Agriculture, Agricultural Research Service, ARS W-53, 1979, p. 89.

GALLO, B.J., R. ANDREOTTI, C.J. ROCH, D. RYU. \& M. MANDELS, 1979. Biotechnology in energy production and conservation (Ed. C.D. S̈cott) pp. 89-101.

GHOSE, T.K., 1972. US Pat. $3642580,5$. GHOSE, T.K. \& J.A. KOSTICK, 1969. In: Cellulases and their applications, advances in chem. Series 95 (Hajny, G.J. and Reese, E.T., eds.) American Chemical Society, washing ton, D.C., p. 415 . 
GHOSE, T.K。 \& P. GHOSE, 1979. Cellulase production and cellulose hydrolysis. Proc. Biochem. 14: 20-24.

GONG, C.S., M.R. LADISH \& G.T. TSAO, 1977. Cellobiase from Trichoderma irridi: Purification, properties, kinects and mechanism. J. Biotechnol. and Bioeng. XIX (7): 959-981.

GUM, E.K. \& R.D. BROWN, 1977. Comparison of four purifield

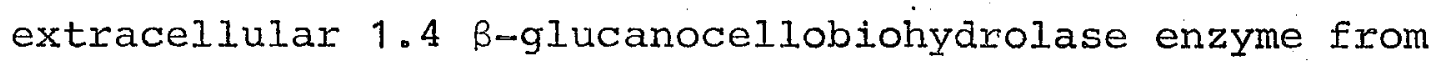
Trichoderma irridi. Biochem. Biophys. Acta 492: 225-231.

HEDGER, J.N., 1982. Rapid screening of cellulolytic acti-..." vity or micro-organisms by the use of acid-swollen cellulose. Micro-organism Meets Plant. p. 617-619.

HOWELL, J.A. \& M. MANGAT, 1978. Enzyme reactivation during. cellulose hydrolysis. J. Biotechnol: Bioeng., 20, 16, $847-863$.

HOWELL, J.A. \& J.D. STUCK, 1975. Kinetcs of solka floc cellulose hydrolysis by "limichoderma viride cellulase. j.Biotechnol. Bioeng. , 17, 5: 873-893.

HUANG, A.A., 1975. Kinetcs studies on insoluble cellulose cellulose-cellulase system. J. Biotechnol. Bioeng.' 17, $10,1421-1433$. 
JANICKI, J., D. GENIBICKA \& K. CHRAPKOWSKA, 1976. J. Pr. Kpm. Nauk. Roln. Kom. Nayk. Lesn., Pozman. Tow Przyj. Nauk. , 41, 117.

JIRESOVA, M. , Z. DOBRAVÄ, J. NAPRSTEK, 1983. Induction of B-D-glucosidase in Streptomyces gramaticolor. Folia Microbiologica 25:380-385.

LEISOLA, M. \& V. KAUPPINEU, 1978. Automatic assay of cellulose activity during fermentation. J. Biotechnol. Bioeng:" 20, $\cdot 6: 837-846$.

MANDELS, M., 1975. In: Cellulose as a chemical and energy resource, biotechnol. Bioeng. Symp. no 5 (Wilke, C.R., ed.) John Wiley and Sons, New York, p. 81.

MANDELS, M., D. STERNBERG \& R.E. ANDREOTTI, 1975. In: Symposium on Enzymatic Hidrolisis of Cellulose (M. Barley, T.M. Enari and M. Linko, eds.). p. 81-SITRA. Aulanko, Finland.

MCCHALE, A.\& M.A. COUGHLAN, 1981. "The cellulolytie systems of Talaromyces emersonii. Identification of the various components produced during growth on cellulosic média". Biochem. Biophys. Acta 662: 145-151.

MITRA, G. \& C.R. WILKE, 1975. Continuous cellulose production. J.Biotechnol. Bioeng., 17, ; 1: 1-13.

MONTENECOURT, B.S., D.E. EVELEGH, G.K. ZLMUND \& J. PARCELLS, 1978. J. Biotechnol. Bioeng., 20, 297. 
MONTENECOURT, B.S. \& D.E. EVELEIGH, 1977. Environ.

Microbiol., 34, 777. Apud: Enzyme Microb. Technol. 1980, 2: $91-102$.

NAKAYAMA, M. J. TONITA, H. SUZUKI \&.K. NISISANA, 1976.

Partial proteolysis of some cellulase. Components from

T. irridi and the substrate specificity of the modified products. J. Biochem. 79: 955.

NIZIZAWA, T., A. SUZUKI, M. NAKAYAMA \& K。 NIZIZAWA, 1971. Inductive formation of cellulase by sophorose in thichoderma irridi. J. of Biochem. Tokyo, 70: 375. NYSTROM, J.M., R.H. ANDRESS \& J.E. MEDEIROS, 1975. Production. of sugar from waste cellulose by enzymatic hydrolisis. Part II. Primary evaluation of substrates. The $170^{\text {th }}$ National A.C.S. Meeting, Chicago, Illinois, 37 p.

PEITERSEN, N., 1977. In: Bioconversion of cellulosic substrances into energy, chemicals and microbial proteins (Ghose, T.K., ed.). Indian Institute of Technology DeIhi, India, p. 281 .

REESE, E.T., 1976. History of the cellulase program at the U.S. Army Natick Development Center. J. Biotechnol. Bioeng. Symp. 6 : $9-20$.

ROMANELII, R.A., C.W. HOUSTON \& S.M. BARNET, 1975. AppIMicrobiol., 30, 276 . 
RYU, D. , R. ANDREOTTI, M. MANDELS, B. GALIO E.T. REESE, s/a. J.Biotechnol.Bioeng. in press.

RYU, D.D., 1980. Cellulases: biossynthesis and applications Enzyme Microb. Technol. 2. 91-102.

SATTAROVA, R.K., 1972. Trashpulatov, Zh. and Safiyazov, Zh. Mikrobiologiya, 41, 413. Apud: Enzyme Microb. Technol., 1980. $2: 91-102$.

SCHEWALE, J.G. \& J.C. SADANA, 1979.. Enzymatic hyärolysis of cellulosic materials by Sclerotium rolfsii culture filtra te from sugar production. Can. J. Microbiol. 25, '6, $773-783$

SMITH, R.E., 1976. Rapid tube test for detecting fungal cellulasès production. $33(1)$ :

p. $980-981$.

SPANO, L.A., J. MEDEIROS \& M. MANDELS, 1975. Enzymatic hydrolysis of cellulosic waste to glucose. U.S. Army Natick-Laboratories, USA. $31 \mathrm{p}$.

SPREY, B。 \& C. LAMBERT, 1984. Heterogeneity of cellulase complexes from Trichoderma reesei: a preparative isoeletric fousing to study of some extracellular hydrolases. FEMS. Microbiol. Let. 23: 227-232。

STERNBERG, G.R. \& M. MANDELS, 1979. "Cellulolytic enzymes in T. Ireesei by shophorose". J.Bacteriol. 139(3): $761-769$ 
STERNBERG, D. \& G.R. MANDELS, 1980. Regulation of the çellulolytic system in Michoderma reesei by sophorose: Induction of cellulase and repression of $\beta$-glucosidase. J. of Bacteriol. $\quad \underline{144,} 3, \quad 1197-1199$.

STERNBERG, D., 1976. B-glicosidase of Trichoderma: its biosynthesis and role in saccharification of cellulose. Appl. Environ. Microbiol. 31: 648-654.

STUPIELO, J.P., 1980. Matérias primas para obtenção de álcool. Fermentações industriais e transformações microbianas no solo. 66-69 (Proc. 29.Simp. Nac. Ferm., Piracicaba, SP). Informações Tec. Cientificas, SBM, SP. (185 p.)

STUTZENBERGER, F.J., 1971: Appl. Microbiol., 22, 147.

TOYAMA, N. \& K. OGAWA, 1977. In: Bioconversion of cellulasic substances into energy, chemicals and microbial proteins (Ghose, T.K., ed.). Indian Institute of Technology Delhi, India, p. 305.

TOYAMA, N., 1976. In: Enzymatic conversion of cellulosic materials: technology and applications. Biotechnol. Bioeng. Symp. no 6 (Gaden, Jr., E.L., Mandels, M.H., Reese, E.T. and Spano, I.A., eds.), John Wiley and Sons, New York, p. 207. 
VILELA, L.C., A.R. TORILLO, A.T. De OCAMPO \& E.J. DEL ROSARIO, 1977. Agric. BioI. Chem. 41, 235.

WILKE, C.R. \& G. MITRA, 1975. In: Cellulose as chemical and energy resource. Biotecnol. Bioeng. Symp. no 5 (Wilke, C.R., ed.), John Wiley and Sons, New York, p. 253.

WILIICK, G., R. MOROSOLI, V.I. SEIIGY, M. YAGUCHI \& M. DESRO CHERS, 1984. Extracellular proteins secreted by the basidiomycete Schizophyllum commune in response to carbon source. J. of Bacteriol. : $\quad$ of 159 , , 294$-299$.

WILLICK, E. \& L. SELIGY, 1985. Multiplicity in cellulases of Schizophyllum commune. Eur. J. Biochem. 151, 89-96. WOOD, T.M., S.I. MCCRAE \& C.M. MEFARLANE, 1980. The isolation, purification and properties of the cellobiohidralase component of Penicillium funiculosum cellulase. Biochem. Journal. 189: 51-65.

WOOD, T.M., 1975. Properties and mode of action of cellulases. Biothenol. and Bioeng. Symp. $\quad 5, \quad \because 111-$ $-137$.

WOOD, T.M. \& S.I. MCCRAE, 1972. The purification and properties of the $\mathrm{C}_{1}$ component of urichoderma konningi cellulose. Biochem. J. 128: 1183-1192. 
WOOD, ri.M. \& S.I. MCCRAE, 1978. In: Bioconversion of cellulosic substance into energy, chemicals \& microbial protein '(Chose, Т.K., ed.) pp. 111-141. H.T. Delhi.

WOOD, T.M. \& S.I. MCCRAE, 1978. The cellulase of Trichoderma konngii. Purification and properties of some endo-glu canase components with special reference to their action on cellulose when acting alone and in synergism with the cellobiohydrolase. Biochem. J. Cambridge. 171: 61-72.

WRIGHT, D.J., 1983. High temperature acid hidrolysis of cellulose for alcohol fuel production. In: "Fall National Meeting" of the American Chemical Society 28 August-September, Washington, D.C. 